\title{
The role of digital breast tomosynthesis in breast cancer screening: a manufacturer- and metrics-specific analysis
}

This article was published in the following Dove Press journal: Cancer Management and Research

\author{
A Hadjipanteli $\mathbb{1}^{1,2}$ \\ $M$ Kontos iD ${ }^{3}$ \\ A Constantinidou (iD) 1,2 \\ 'Medical School, University of Cyprus, \\ Nicosia, Cyprus; ${ }^{2}$ Bank of Cyprus \\ Oncology Centre, Nicosia, Cyprus; ${ }^{3}$ Ist \\ Department of Surgery, National and \\ Kapodistrian University of Athens, \\ Athens, Greece
}

\begin{abstract}
Aim: Digital Breast Tomosynthesis (DBT), with or without Digital Mammography (DM) or Synthetic Mammography (SM), has been introduced or is under consideration for its introduction in breast cancer screening in several countries, as it has been shown that it has advantages over DM. Despite this there is no agreement on how to implement DBT in screening, and in many cases there is a lack of official guidance on the optimum usage of each commercially available system. The aim of this review is to carry out a manufacturerspecific summary of studies on the implementation of DBT in breast cancer screening.

Methods: An exhaustive literature review was undertaken to identify clinical observer studies that evaluated at least one of five common metrics: sensitivity, specificity, area under the curve (AUC) of the receiver-operating characteristics (ROC) analysis, recall rate and cancer detection rate. Four common DBT implementation methods were discussed in this review: (1) DBT, (2) DM with DBT, (3) 1-view DBT with or without 1-view DM or 2-view DM and (4) DBT with SM.

Results: A summary of 89 studies, selected from a database of 677 studies, on the assessment of the implementation of DBT in breast cancer screening is presented in tables and discussed in a manufacturer- and metric-specific approach. Much more studies were carried out using some DBT systems than others. For one implementation method of DBT by one manufacturer there is a shortage of studies, for another implementation there are conflicting results. In some cases, there is a strong agreement between studies, making the advantages and disadvantages of each system clear.
\end{abstract}

Conclusion: The optimum implementation method of DBT in breast screening, in terms of diagnostic benefit and patient radiation dose, for one manufacturer does not necessarily apply to other manufacturers.

Keywords: digital breast tomosynthesis, breast cancer screening

\section{Introduction}

Breast cancer is the most common type of cancer in women worldwide, and the second most common cause of cancer death in women in developed countries. ${ }^{1,2}$ For its early diagnosis breast cancer screening programs are available in many countries across the world. In many countries this involves the use of 2D digital mammography (DM), an X-ray 2D imaging technique. ${ }^{3}$ Women within a certain age range (often 40-70 years, depending on country) are called to attend breast cancer screening, over regular periods in their lifetime (normally every 1-3 years, depending on country), with the aim to diagnose the disease at an earlier than the
Correspondence: A Hadjipanteli

Shacolas Educational Centre for Clinical

Medicine, Palaios dromos Lefkosias Lemesou,

No. 2I 5/6, 2029 Aglantzia, P.O. Box 20537

Nicosia 1678, CY, USA

Email hadjipanteli.andria@ucy.ac.cy 
symptoms appearance stage and reduce the risk of death from breast cancer. Breast cancer screening mortality from breast cancer can been reduced by $25-31 \%$ among invited women and 38-48\% among those who actually attended screening. ${ }^{4}$

\section{Technology}

In DM, images of the breast are acquired in two views, the craniocaudal (CC) and the mediolateral oblique (MLO), for assessment, even though three-view DM has also been considered. ${ }^{5}$ Assuming "head to toes" of a standing patient undergoing breast imaging on a DM system is the z-axis, and the detector surface is below the patient breast and perpendicular to the z-axis, $\mathrm{CC}$ is a view in the direction "head to toes" and parallel to the z-axis, while MLO is a view at an angle less than $\pm 90^{\circ}$ to the z-axis.

Digital breast tomosynthesis (DBT) is a more advanced breast cancer imaging technique, with an acquisition geometry very similar to that used in DM. It involves the acquisition of low-dose 2D X-ray projection images of the breast over a limited angular range. For the projections acquisition, the X-ray tube rotates around the static and compressed breast (Figure 1). A reconstruction algorithm is then used to process the projections and reconstruct a quasi-3D image and image planes, parallel to the detector. This algorithm uses the different locations in the projections of the same tissue to compute their vertical position, thereby estimating the 3D distribution of the tissue. DBT images can be acquired in both CC and MLO views, as in DM (Figure 1). The dose of a single view DBT is $2.19 \mathrm{mGy}$ for $50-60 \mathrm{~mm}$ thick breasts, which is slightly higher than the corresponding one-view DM of $1.88 \mathrm{mGy}^{6}$

Some of the DM and DBT manufacturers provide an additional imaging modality together with DBT called synthetic mammography (SM). SM involves the synthesis of a DM image of the breast using the 2D projection images acquired using DBT, at no cost of any additional dose. A mathematical algorithm is applied to the acquired DBT projections by summing and filtering the stack of reconstructed sections. A region of interest in the synthesized image can then be contrast-enhanced using mathematical filters.

\section{Current status}

Digital Breast Tomosynthesis (DBT), with or without Digital Mammography (DM) and/or Synthetic Mammography (SM), has been introduced in breast cancer screening by



Figure I Breast digital tomosynthesis projection acquisition (CC-view): the X-ray source rotates around the static and compressed breast over a limited angular range, while the detector is static or rotates slightly.

national breast screening programs in some countries, ${ }^{7}$ it is under consideration for its introduction in others, ${ }^{8,9}$ while independent practices might create their own implementation protocols. There is currently no standardisation on if and how to implement DBT in screening, and in many cases there is lack of official guidance on the optimum usage of each commercially available system.

Several national breast screening programs and independent breast screening centres are independently investigating the implementations with which DBT could be introduced in breast cancer screening. DBT has been considered being used in screening alone, thus fully replacing DM. DBT has also been considered being used in combination with $\mathrm{DM}$ or in combination with SM, with SM replacing DM. Investigations to introduce one view of DBT only, with or without DM, have also been carried out. 
Clinical observer studies are widely used for the assessment of the different implementations with which DBT can be introduced in screening. The process of clinical observer studies involves the acquisition and use of either prospective or retrospective realistic breast cancer images under specific implementations, and their observation by real observers (normally radiologists) under clinically relevant conditions. The outcome of these studies is the evaluation of metrics that assess the performance of systems. Often the following metrics are assessed: sensitivity (true positive rate), specificity (true negative rate), recall rate and cancer detection rate (the number of cancers detected per 1000 screening mammograms) of the different implementations and their direct comparison. In addition, the receiver operating characteristics (ROC or JAFROC) analysis is commonly undertaken for the evaluation of the area under curve (AUC) of the ROC curve (sensitivity versus 1-specificty), which represents how well a DBT implementation can distinguish between two diagnostic groups. ${ }^{10}$ In JAFROC analysis, AUC represents a figure of merit defined as the probability that a correctly marked lesion is rated higher than the highest-rated mark on a normal or benign case. ${ }^{11}$

\section{This work}

A lot of review work has been completed on the use of DBT in breast cancer screening. ${ }^{8,12,13}$ However, to the best of our knowledge, no review work has summarised clinical observer studies separately for each of the four common methods with which DBT can be implemented in screening:

1. (2-view) DBT alone [DBT or 2vDBT],

2. (2-view) DBT with (2-view) DM [DM\&DBT],

3. Single-view DBT [1vDBT] with or without single or double view DM [1vDM or $2 \mathrm{vDM}$ ],

4. (2-view) DBT with (2-view) SM [DBT\&SM].

Furthermore, DBT systems by different manufacturers vary to a big extent in terms of technical specifications. DBT variations between manufactures include the geometry of the system, including the number of projection images and the angular range over which they are obtained, the height of the center of rotation of the tube in relation to the detector surface, whether the projection images are obtained while the tube is in motion, or with a step and-shoot process. Other variations between different DBT systems might include whether an antiscatter grid is used, the reconstruction algorithm, the pixel size of the reconstructed images and the dose levels. The system design details normally involve a trade-off. For example, a wider angular range is expected to enhance in-depth resolution, which might aid radiological interpretation, but this comes at the cost of lower in-plane resolution. Therefore, when assessing DBT implementations it is important to assess each manufacturer separately.

The aim of this review is to carry out a manufacturerand metric- specific summary of studies on four common DBT implementations. The aim is not to support any of the DBT implementation methods, but only to distinguish them and provide a summary of studies for each of them. This could make healthcare providers more aware of the advantages and limitations of each implementation method of each DBT system.

\section{Materials and methods}

An exhaustive literature search was undertaken using the pubmed search engine and the quotation "tomosynthesis breast cancer screening". Six hundred and seventy seven (677) studies published from November 1997 to December 2018 were identified. As a minimum the abstracts of all studies were reviewed to consider whether the study meets the inclusion criteria. For studies to meet the inclusion criteria they needed to include:

- the comparison of at least one of the four implementations discussed in section "Introduction": (1) DBT, (2) DM\&DBT, (3) $1 \mathrm{vDBT}$ with or without $1 \mathrm{vDM}$ or 2vDM and (4) DBT\&SM, directly with DM alone and/or with each other, and

- the assessment of at least one of the five metrics: (a) sensitivity, (b) specificity, (c) AUC of the ROC or JAFROC analysis, (d) recall rate and (e) cancer detection rate.

Out of the 677 studies identified through the pubmed search engine, non-English studies and studies that included the evaluation of other breast imaging modalities, other than DM and DBT, were excluded. The rest of the articles were then divided into different types of articles based on their type (original studies, reviews and documents, guidelines and position papers, case studies, financial studies, surveys and others). The original studies were read in most detail and were separated into groups based on the methodologies that were used 
(clinical, development and technical, simulation and theoretical, characterization and features). Development and technical studies included those that studied the development and/or evaluation of prototypes, reconstruction algorithms, computer-aided diagnosis, measurement of radiation dose, time, effect of density in imaging and biopsy techniques. The studies that used clinical data (real patient images, defined as clinical studies) were further studied. Of those, 141 were included in this review. Common metrics that were assessed in original clinical studies, which were excluded from the review (Figure 2, non-eligible papers), included the size of lesions, type of lesions, BIRADS score, mass visibility, time of interpretation and breast density. Clinical studies on surveillance imaging and the role of access to prior mammograms, as well as studies that did not include enough details on their methodology were also excluded. A summary of the strategy and scope, the number of identified articles and the number considered eligible for inclusion in this review are shown in Figure 2.

\section{Results: studies on the optimal use of digital breast tomosynthesis in screening}

This section presents the evidence (necessary details of each original study including methods, results and conclusions) in subjections "Sensitivity", "Specificity", "AUC", "Recall rate", "Cancer detection rate" that may lead, where possible, to conclusions for the optimal use of each DBT implementation (subjections Summary). To act as a quick reference tool for readers, the results are systematically described (in the four sections below; "Digital breast tomosynthesis alone versus digital mammography", "Digital breast tomosynthesis with digital mammography versus digital mammography", "Single view digital breast tomosynthesis versus digital mammography" and "Digital breast tomosynthesis with synthetic mammography versus digital mammography") for each of the four common implementations with which DBT could be used in screening: (1) DBT, (2) DM\&DBT, (3) 1vDBT with or without 1vDM or 2vDM and (4) DBT\&SM. Each implementation method is compared to the current practice gold



Figure 2 The strategy and scope of this review, the number of identified articles and the number considered eligible for inclusion in this work. The decision taken at each step of the eligibility process is shown in a red box. 
standard, 2-view DM alone, and/or with each other. For each implementation method, the literature corresponding to the five metrics in question (sensitivity, specificity, AUC, recall rate, cancer detection rate) are separately discussed. The results section is therefore split into 20 different subsections in total.

In this section we report the findings of the authors; namely if the authors consider a result to be "statistically significant" then we report it here as "significant". However, each study might use a different criterion for statistical significance, so readers are encouraged to read the individual papers for further details. Direct comparison of different technologies even by the same manufacturer is difficult, therefore in this work, the version of the system used in each original study is specified, where appropriate.

\section{Digital breast tomosynthesis alone versus digital mammography}

Many imaging centres may consider replacing DM with the new and more advanced DBT systems, due to its 3D capabilities. However, for DBT alone to fully replace DM in breast cancer screening it would have to provide at least the same diagnostic capabilities with DM, at similar dose levels. Normally, the mean glandular dose levels by 1vDBT are considered $1-1.5$ times that of $1 \mathrm{vDM} .^{6,14}$ This section presents clinical observer studies that investigated whether DBT by different manufacturers have shown any outperformance in comparison to DM, in terms of sensitivity, specificity, AUC, recall rate and cancer detection rate. Tables 1 and 2 summarize the studies that were identified for the purposes of this review for the comparison of DBT alone to DM alone.

\section{Sensitivity}

Originally, DBT was assessed for its potential value as an additional technique following DM in patients referred with an abnormal screening mammogram or with clinical symptoms. ${ }^{15}$ In this prospective study, Teertstra et al assessed DBT versus DM separately, using Hologic systems (Lorad Selenia, an older version of Hologic DM and a prototype

Table I Sensitivity, specificity and AUC - comparison of DBT alone to DM

\begin{tabular}{|c|c|c|c|c|c|c|}
\hline Author & Year & Vendor & $\mathbf{N}$ & Sensitivity & Specificity & AUC \\
\hline Asbeutal et al & 2018 & GE & 58 & DM: $73.5 \%$, DBT: $100 \%[Y]$ & DM: 67.7\%, DBT: 94\% [Y] & DM: $0.706, \mathrm{DBT}: 0.984[\mathrm{Y}]$ \\
\hline Bian et $\mathrm{al}^{\mathrm{c}}$ & 2016 & Hologic & 631 & DM 58.8\%, DBT: $68.1 \%[Y]$ & DM: $86.7 \% \%$, DBT: $95.2 \%[Y]$ & - \\
\hline Brandt et $\mathrm{al}^{\mathrm{b}}$ & 2013 & Hologic & 146 & DM: $100 \%$, DBT: $88-100 \%$ & DM: 94\%, DBT: 89—94\% & - \\
\hline Clauser et $\mathrm{al}^{\mathrm{a}}$ & 2016 & $\begin{array}{l}\text { DM: Siemens, } \\
\text { GE, Sectra } \\
\text { DBT: Siemens }\end{array}$ & 150 & DM: 88-90\%, DBT: 78—98\% & - & DM: 0.829, DBT: 0.833 \\
\hline Dibble et al ${ }^{d}$ & 2018 & Hologic & 118 & DM: $32 \%$, DBT: $59 \%[Y]$ & DM: $93 \%, \mathrm{DBT}: 93 \%[\mathrm{~N}]$ & DM: $<0.75, \mathrm{DBT}:>0.75$ \\
\hline Good et al & 2008 & Hologic & 30 & - & - & DM: $0.60, \mathrm{DBT}: 0.62[\mathrm{~N}]$ \\
\hline Li et $\mathrm{al}^{\mathrm{a}}$ & 2018 & Hologic & 305 & DM: $88.8 \%, \mathrm{DBT}: 92.9 \%[\mathrm{~N}]$ & DM 75.2\%:, DBT: $87.9 \%[Y]$ & - \\
\hline Seo et al & 2016 & Hologic & 203 & DM: 73.2\%, DBT:78.3\% [Y] & DM: $61 \%, \mathrm{DBT}: 63 \%[\mathrm{~N}]$ & DM: 0.775, DBT: 0.807 [Y] \\
\hline Spangler et $\mathrm{al}^{\mathrm{a}}$ & 2011 & Hologic & 100 & DM: $84 \%$, DBT: $75 \%$ & DM: $71 \%$, DBT: $64 \%$ & DM: $0.76, \mathrm{DBT}: 0.72[\mathrm{~N}]$ \\
\hline Tagliafico et $\mathrm{al}^{\mathrm{a}}$ & 2015 & Hologic & 107 & DM: $100 \%$, DBT: $91.1 \%$ & DM: $94.6 \%, \mathrm{DBT}: 100 \%$ & - \\
\hline Terrstra et al & 2010 & Hologic & 513 & DM: $92.9 \%, \mathrm{DBT}: 92.9 \%[\mathrm{~N}]$ & DM: $86.1 \%$, DBT: $84.4 \%$ & - \\
\hline Wallis et al & 2012 & Sectra & 130 & - & - & $\begin{array}{l}\text { DM: } 0.772, \mathrm{DBT}: 0.85 \mathrm{I} \text { (Y for } \\
\text { readers with least experience), } \\
\text { IvDBT: } 0.775[\mathrm{~N}]\end{array}$ \\
\hline
\end{tabular}

Notes: ${ }^{a}$ Calcifications; ${ }^{b}$ Non-calcified lesions; ${ }^{\mathrm{C}}$ Masses, dense breast; ${ }^{\mathrm{d}}$ Architectural distortions. $[\mathrm{Y}]=$ statistically significant, $[\mathrm{N}]=$ non-statistically significant, where available.

Table 2 Recall rate and cancer detection rate - Comparison of DBT alone to DM

\begin{tabular}{|c|c|c|c|c|c|}
\hline Author & Year & Vendor & $\mathbf{N}$ & Recall rate & $\begin{array}{l}\text { Cancer detection rate } \\
{[/ 1000]}\end{array}$ \\
\hline Aase et al & 2018 & GE & 14,274 & DBT: $3 \%$, DM: $3.6 \%[Y]$ & - \\
\hline Bian et $\mathrm{al}^{\mathrm{a}}$ & 2016 & Hologic & 631 & DM: $9.8 \%$, DBT: $3.6 \%[Y]$ & - \\
\hline $\begin{array}{l}\text { Giess et } \\
\text { al }\end{array}$ & 2017 & Hologic & 37,338 & DM: $10.3 \%, \mathrm{DBT}: 10.7 \%[\mathrm{~N}]$ & DM: I.8, DBT: $3.8[Y]$ \\
\hline $\begin{array}{l}\text { Good et } \\
\text { al }\end{array}$ & 2008 & Hologic & 30 & $\begin{array}{l}\text { Malign. DM: } 90.9 \% \text {, DBT: } 93.9 \% \text {, non-malign: DM: } 64.3 \% \text {, DBT: } 62.6 \% \\
{[\mathrm{~N}]}\end{array}$ & - \\
\hline
\end{tabular}

Note: ${ }^{a}$ Masses, dense breast; $[\mathrm{Y}]=$ statistically significant, $[\mathrm{N}]=$ non-statistically significant, where available. 
DBT) and 503 participants. No difference in sensitivity between the two systems was found. Later, Seo et al, ${ }^{16}$ in a study with Hologic Selenia Dimensions systems (most recent Hologic DM and DBT version) and 203 participants concluded that DBT has a higher sensitivity than DM.

A few studies on Hologic investigated the performance of DBT in comparison to DM, for different forms of breast cancer separately. Brandt et al (2013) carried out a study for noncalcifying lesions only and DBT was found to have similar sensitivity to DM. Bian et $\mathrm{al}^{17}$ found a statistically higher sensitivity for DBT than for DM for the detection of masses, specifically in dense breasts. On the other hand, other studies, which focused on calcifications only, found the sensitivity of DBT to be lower than DM, with the conclusion that DBT might miss a small number of this form of breast cancer. ${ }^{18,19}$

With the above results, one could conclude that if either DM alone or DBT alone is used in breast screening, one form of breast cancer might be more likely to be missed. These concerns lead to some simulation studies using realistic breast tissue and real observers aiming to explain the above findings. It was concluded that DBT can outperform DM in masses detectability. ${ }^{20,21}$ However, the minimum detectable calcification diameter of DM and DBT were found to be 164 $\pm 5 \mu \mathrm{m} 210 \pm 5 \mu \mathrm{m}$ respectively at standard dose. ${ }^{22}$ This difference in calcification diameter was explained by the lower sharpness and the lower modulation transfer function of DBT (Hologic Selenia Dimensions) compared to DM. DBT has a larger pixel pitch, due to pixel binning, as well as X-ray tube movement that introduces blurring. ${ }^{23}$ In addition, a slight further increase in geometric blurring might be introduced as the projection angle becomes wider. ${ }^{24}$

However, conflicting conclusions were drawn in a recent study $^{25}$ where it was shown that calcifications can be diagnosed using DM and DBT with similar sensitivity. Sensitivity for architectural distortions was also studied separately and DBT alone was found to outperform DM. $^{26}$ The implementation of Hologic DBT alone in breast cancer screening remains controversial in research studies. However, conclusions from the above studies on Hologic do not necessarily apply to other manufacturers.

Studies using the Siemens DBT system include the one by Clauser et $\mathrm{al}^{27}$ in which microcalcifications only were investigated and an increased sensitivity with Siemens DBT was demonstrated compared to DM alone. It is worth noting though that the DM images were acquired with three different systems; Siemens, Sectra and GE, therefore DM and DBT compared are not of the same manufacturer in this case.
In a study using the Senographe Essential (GE Healthcare) system $^{28}$ a significant outperformance was observed for $2 \mathrm{vDBT}$ in comparison to $2 \mathrm{vDM}$ in terms of sensitivity.

\section{Specificity}

A small (non-significant) difference in specificity between DM and DBT were drawn in two studies for Hologic Selenia Dimensions systems. ${ }^{15,16}$ Regarding calcifications detection, two studies have shown that DBT outperforms DM in terms of specificity, ${ }^{18,25}$ while an only slightly better DBT performance was found by Spangler et al. ${ }^{19}$ Specificity was found to be similar between DM and DBT for architectural distortions ${ }^{26}$ and for non-calcifying lesions ${ }^{17,29}$ specifically for dense breasts, and for architectural distortions. ${ }^{26}$

In a relatively small study (58 participants) GE DBT was found to outperform DM in terms of specificity. ${ }^{28}$

\section{AUC}

In terms of AUC, a non-statistically significant difference between the performances of DM and DBT for Hologic, was found in two studies, ${ }^{19,30}$ showing that the two imaging systems could equally distinguish between a cancerous and a non-cancerous group. Conflicting results were found by Seo et al $2016 .{ }^{16}$ Larger studies are required to support these studies' results and draw final conclusions on AUC, as their sample number is relatively small (30, 100 and 203 patients for ${ }^{16,19,30}$ respectively). Regarding architectural distortions, Dibbie et $\mathrm{al}^{26}$ have shown a higher AUC with DBT alone compared to DM.

For microcalcifications, a non-statistically significant increase in AUC was found for Siemens DBT systems compared to $\mathrm{DM}^{27}$

Wallis et al (2012) carried out a study using the Sectra photon counting DBT system. ${ }^{31}$ A significantly lower AUC was found for DM versus 2vDBT only when taking into account the results of the least experienced readers (five out of ten readers with less than 10 years of mammography experience).

\section{Recall rate}

In two studies using Hologic ${ }^{30,32}$ a non-significant difference was found in the recall rate of the two imaging systems. On the other hand, a different study reported a significantly lower recall rate by DBT. ${ }^{17}$

For GE, Aase et $\mathrm{al}^{33}$ reported a recall rate of $3.0 \%$ and $3.6 \%$ for DBT and DM respectively, a difference that was statistically significant. 


\section{Cancer detection rate}

For Hologic, a significantly higher cancer detection rate was found for DBT alone versus DM alone. ${ }^{32}$

\section{Summary}

In this section a comparison between DM alone and DBT alone was performed based on research studies. More studies were performed for some manufacturers than others and different conclusions can be drawn for different manufacturers. Studies using the most recent Hologic systems show that DBT alone might demonstrate better performance in terms of specificity and DM in terms of sensitivity, especially in the detection of calcifications, although not all studies reach this conclusion. AUC and recall rate seem to be at least similar for the two imaging systems, while a higher cancer detection rate was found for DBT. Studies on GE DBT have conflicting results, while Sectra results of one study show dependency on observer experience.

\section{Digital breast tomosynthesis with digital mammography versus digital mammography}

It is often suggested by manufacturers that both DM and DBT should be used together (DM\&DBT) in breast cancer screening. Some limitations include the increased reading time and image storage capacity. The main concern of introducing single or double-view DBT in screening together with DM is the additional dose to the patient or to the healthy woman who attends screening for early breast cancer diagnosis. There is the radiation protection requirement to keep the dose as low as reasonably practicable or in other words, to make sure that the diagnostic advantage of DBT outweighs the additional dose to the patient. Studies that investigated the diagnostic advantage of DM\&DBT versus DM in terms of sensitivity, specificity, AUC, recall rate and cancer detection rate are summarised in Tables 3 and 4 and are discussed below.

\section{Sensitivity}

A pilot observer study that compared DM to DM\&DBT (DBT model: Genesis Tomosynthesis System, Hologic) was originally performed by with 30 participants. ${ }^{34}$ Results showed no improvement in observer performance with the addition of DBT. Later studies concluded that observer performance increases with the addition of DBT to DM when using more advanced Hologic models. ${ }^{13,16,35-43}$ Specifically in the detection and characterization of invasive lobular cancers, DM\&DBT significantly increases sensitivity compared to DM alone. ${ }^{44}$

The TOMMY trial, carried out with 7060 patients in the United Kingdom, showed a marginal increase in sensitivity with borderline significance, with the addition of DBT to $\mathrm{DM},{ }^{45}$ while Tucker et al, using the same data concluded that sensitivity was increased for observers with less than 10 years of experience with the addition of DBT. ${ }^{46}$

Recently, Skaane et $\mathrm{al}^{7}$ carried out a study, using the Oslo Trial data, in which 24,301 images acquired with DM\&DBT were compared to 59,877 DM images of the same women acquired during prior rounds. Results showed that the addition of DBT gives a non-significant increase in sensitivity. In other large studies of 198,881 and 325,729 participants respectively, a non-significant difference in sensitivity was also found between DM and DM\&DBT. ${ }^{47,48}$

The majority of the above Hologic studies show an increase in sensitivity with the addition of DBT to DM, however, the three large studies in terms of participants' number, reported no statistical significance.

Not many studies were completed to date for other manufacturers. A retrospective study for GE was completed recently using $628 \mathrm{DM}$ and DBT images from patients that had undergone mammography screening and had abnormal screening results or clinical symptoms. A statistically significant increase in sensitivity was found when adding DBT to DM. ${ }^{49}$

\section{Specificity}

Some studies show a significantly higher specificity with the addition of DBT to DM in screening. ${ }^{7,36,37,42,46,48,50,51}$ Other studies, however, concluded that there was a non-statistically significant increase. ${ }^{16,39,41}$ It should be noted that the three latter studies have in common a relatively small number of participants (100-200 women). Specifically, for "extremely dense breasts" Yi et al ${ }^{35}$ found a non-statistically significant difference in the specificity of the systems.

In the only GE study a statistically significant difference was found for specificity for DM\&DBT over DM. ${ }^{49}$

\section{AUC}

In 2011, Gur et al reported a better performance, in terms of AUC, for DM\&DBT versus DM alone. ${ }^{52}$ In a similar study ${ }^{36}$ AUC was found to be significantly better for Hologic DM\&DBT than for DM alone, for masses, and only slightly better, for calcifications. Similar conclusions were later drawn in other studies for Hologic ${ }^{37,50}$ for all breast cancer 
Table 3 Sensitivity, specificity and AUC - comparison of DM\&DBT to DM alone, for all lesion types

\begin{tabular}{|c|c|c|c|c|c|c|}
\hline Author & Year & Vendor & $\mathbf{N}$ & Sensitivity & Specificity & AUC \\
\hline Alakhras et al & 2015 & Hologic & 50 & $\begin{array}{l}\text { DM: } 63.0 \%, \text { DM\&DBT: } 70.4 \% \\
{[Y]}\end{array}$ & $\begin{array}{l}\text { DM: } 65.2 \%, \text { DM\&DBT: } 78.3 \% \\
{[Y]}\end{array}$ & $\begin{array}{l}\text { DM: } 0.68 I, \text { DM\&DBT: } \\
0.788[Y]\end{array}$ \\
\hline Alsheik et al & 2018 & $\begin{array}{l}\text { Hologic, } \\
\text { Siemens }\end{array}$ & 325,729 & $\begin{array}{l}\text { DM: } 87.9 \%, \text { DM\&DBT: } \\
92.0 \%[\mathrm{~N}]\end{array}$ & $\begin{array}{l}\text { DM: } 89.5 \%, \text { DM\&DBT: } \\
91.5 \%[Y]\end{array}$ & - \\
\hline Bansal et al & 2015 & Hologic & 103 & - & - & $\begin{array}{l}\text { DM: } 0.72 \mathrm{I}, \mathrm{DM} \& \mathrm{DBT}: \\
0.90 \mathrm{I}[\mathrm{N}]\end{array}$ \\
\hline Bernardi et al & 2018 & Hologic & 9672 & $\begin{array}{l}\text { DM: } 46-100 \% \text {, DM\&DBT: } \\
56-76 \%\end{array}$ & - & - \\
\hline Conant et al & 2016 & Hologic & $198,88 \mid$ & DM: $90.6 \%, \mathrm{DBT}: 90.9 \%$ [N] & DM: 89.7\%, DBT: 91.3\% [Y] & - \\
\hline Endo et al & 2017 & Fujifilm & 471 & - & - & $\begin{array}{l}\text { DM: } 0.750, \text { DM\&DBT: } \\
0.779-0.799[Y]\end{array}$ \\
\hline Gillbert et al & 2015 & Hologic & 7060 & $\begin{array}{l}\text { DM: 87\%, DM\&DBT: } 89 \% \\
{[Y]}\end{array}$ & $\begin{array}{l}\text { DM: } 58 \%, D M \& D B T: 69 \% \\
{[Y]}\end{array}$ & $\begin{array}{l}\text { DM: 0.84, DM\&DBT: } \\
0.89[Y]\end{array}$ \\
\hline Gur et al & 2011 & Hologic & 125 & - & - & $\begin{array}{l}\text { DM\&DBT: } 16 \% \\
\text { increase }\end{array}$ \\
\hline Houssami et al & 2014 & Hologic & 7292 & DM: 54\%, DM\&DBT: $85 \%$ & - & - \\
\hline Kim et al & 2017 & & 116 & DM: $58.3 \%$, DBT\&DM: $69.4 \%$ & DM: 84. I\%, DM\&DBT: $85.9 \%$ & - \\
\hline Mall et al & 2018 & Hologic & 144 & DM: $90 \%$, DBT: $93 \%$ & DM: 0.56, DM\&DBT: 0.75 & $\begin{array}{l}\text { DM: } 0.872, \text { DM\&DBT: } \\
0.927\end{array}$ \\
\hline Mariscotti et al & 2016 & & 83 & DM: 70\%, DBT\&DM: 85\% [Y] & - & $\begin{array}{l}\text { DM: 0.84, DBT\&DM: } \\
0.89\end{array}$ \\
\hline Michell et al & 2012 & Hologic & 738 & DM: $40 \%$, DM\&DBT:58\% & DM: 5I\%, DM\&DBT: 74.2\% & $\begin{array}{l}\text { Significantly higher for } \\
\text { DM\&DBT for masses, } \\
\text { slightly higher for } \\
\text { DM\&DBT for calcs }\end{array}$ \\
\hline Ohashi et al & 2018 & GE & 628 & DM: $61 \%$, DM\&DBT: $83 \%$ & $\begin{array}{l}\text { DM: } 99.1 \%, \text { DM\&DBT: } \\
98.9 \%\end{array}$ & $\begin{array}{l}\text { DBT\&DM:0.9376, } \\
\text { DM:0.9160 [N] }\end{array}$ \\
\hline Rafferty et al & 2013 & Hologic & 1192 & $11-16 \%$ increase with DBT & $\begin{array}{l}\text { DM }(-) 2 \% \text { to } 5 \% \text { difference } \\
\text { with DBT }\end{array}$ & $\begin{array}{l}6.8-7.2 \% \text { increase with } \\
\text { the addition of DBT }\end{array}$ \\
\hline Seo et al & 2016 & Hologic & 203 & $\begin{array}{l}\text { DM\&DBT: } 80 \%, \text { DM: } 73.2 \% \text {, } \\
\text { DBT:78.3\% [Y] }\end{array}$ & $\begin{array}{l}\text { DM: } 61 \%, \text { DBT: } 63 \% \text {, } \\
\text { DM\&DBT: } 64.3 \%[N]\end{array}$ & $\begin{array}{l}\text { DM\&DBT: } 0.827, \mathrm{DM}: \\
0.775, \mathrm{DBT}: 0.807[\mathrm{Y}]\end{array}$ \\
\hline Singla et al & 2018 & Hologic & 100 & DM: $83.6 \%$, DM\&DBT: $100 \%$ & DM: 38.78\%, DM\&DBT: $76.4 \%$ & - \\
\hline Skaane et al & 2018 & Hologic & 84,178 & $\begin{array}{l}\text { DM: } 76.2 \%, \text { DM\&DBT: } \\
80.8 \%[\mathrm{~N}]\end{array}$ & $\begin{array}{l}\text { DM: } 96.4 \%, \text { DM\&DBT: } \\
97.5 \%[Y]\end{array}$ & - \\
\hline Thomassin-Naggara et al & 2015 & Hologic & 155 & $\begin{array}{l}\text { DM: } 72.9 \%, \\
\text { DM\&DBT:89.3\% [Y] }\end{array}$ & $\begin{array}{l}\text { DM: } 50.5 \%, \text { DM\&DBT: } \\
50.7 \%[\mathrm{~N}]\end{array}$ & - \\
\hline Tucker et al & 2017 & Hologic & 7060 & $\begin{array}{l}\text { DM: } 86 \%, \text { DM\&DBT:91\% [Y, } \\
\text { for }<10 \text { years of } \\
\text { experience] }\end{array}$ & DM: $56 \%$, DM\&DBT: $68 \%$ & - \\
\hline Yi et $\mathrm{al}^{\mathrm{a}}$ & 2018 & Hologic & 265 & $\begin{array}{l}\text { DM: } 59.1 \%, \text { DM\&DBT: } \\
63.6 \%[\mathrm{~N}]\end{array}$ & $\begin{array}{l}\text { DM: 75.8\%, DM\&DBT: } \\
84.8 \% 75.8 \%[\mathrm{~N}]\end{array}$ & - \\
\hline
\end{tabular}

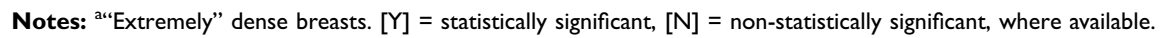

mammographic appearances, and for invasive lobular cancers specifically. ${ }^{53}$ On the contrary to the above, a different study has shown a non-significant increase in AUC with the addition of DBT to DM. ${ }^{54}$

In a GE study no significant difference was found for AUC for DM and DM\&DBT. ${ }^{49}$

In the only Fujifilm study identified for the purposes of this review, it was found that DM\&DBT, in both modes (standard and high-resolution mode), outperforms DM alone in terms of AUC. ${ }^{55}$

\section{Recall rate}

Table 4 shows the results of the large number of studies on the comparison of the recall rate between DM and DM\&DBT. For Hologic, there is a consistent agreement among all studies; they all show a decrease 
Table 4 Recall rate and cancer detection rate - comparison of DBT\&DM to DM

\begin{tabular}{|c|c|c|c|c|c|}
\hline Author & Year & Vendor & $\mathbf{N}$ & Recall rate & Cancer detection rate $[/ 1000]$ \\
\hline Alsheik et al & 2018 & $\begin{array}{l}\text { Hologic, } \\
\text { Siemens }\end{array}$ & 325,729 & DBT\&DM: $8.83 \%$, DM: $10.98 \%[Y]$ & DM: 3.8, DBT\&DM: $4.8[\mathrm{Y}]$ \\
\hline Bahrs et $\mathrm{al}^{\mathrm{b}}$ & 2018 & Hologic & 87 & $57.1 \%$ decrease with DBT & - \\
\hline Bernardi et al & 2018 & Hologic & 9672 & DM\&DBT: $1.6-4.6 \%$, DM: $1.2-2.7 \%$ & Increased CDR between 0-3.5 \\
\hline Carbonaro et al & 2016 & Giotto & 280 & $\begin{array}{l}\text { DM: } 72-84 \% \text { ( } 92 \% \text { double reading), } \\
\text { DM\&DBT: } 42-57 \% \text { ( } 57 \% \text { double } \\
\text { reading) }\end{array}$ & - \\
\hline Cohen et al & 2018 & Hologic & 103,070 & DM: 7.9\%, DM\&DBT: $6.1 \%[Y]$ & DM: 4.0, DM\&DBT: $4.8[\mathrm{~N}]$ \\
\hline Conant et al & 2016 & Hologic & $|98,88|$ & DM: $10.4 \%, \mathrm{DBT}: 8.7 \%[\mathrm{Y}]$ & DM: 4.4, DM\&DBT: 5.9 [Y] \\
\hline Destounis et al & 2014 & Hologic & 524 & DM: II.45\%, DM\&DBT: $4.2 \%$ [Y] & DM: 3.8, DM\&DBT: 5.7 [Y] \\
\hline Durand et al & 2015 & Hologic & 17,955 & DM: I2.3\%, DM\&DBT: $7.8 \%[Y]$ & - \\
\hline Friedewald et al & 2014 & Hologic & 454,850 & DM: $10.7 \%$, DM\&DBT: $9.1 \%[Y]$ & DM: 4.2, DM\&DBT: $5.4[Y]$ \\
\hline Greenberg et al & 2014 & Hologic & 77,833 & DM: $16.2 \%$, DBT\&DM: $13.6 \%[Y]$ & DM:4.9, DM\&DBT: 6.3 [Y] \\
\hline Gur et al & 2009 & Hologic & 125 & $30 \%$ decrease with DBT & - \\
\hline Haas et al & 2013 & Hologic & 13,158 & DM: $12 \%$, DM\&DBT: $8.4 \%[Y]$ & DM: 5.2, DM\&DBT: $5.7[\mathrm{~N}]$ \\
\hline Hakim et al & 2014 & Hologic & 36 & DM: $67 \%$, DM\&DBT: $42 \%[Y]$ & - \\
\hline Houssami et al & 2014 & Hologic & 7292 & DM: $4.2 \%$, DM\&DBT: $5.3 \%{ }^{\mathrm{a}}$ & DM: 4.8, DM\&DBT: 7.5 [Y] \\
\hline Lourenco et al & 2015 & $\begin{array}{l}\text { GE, } \\
\text { Hologic }\end{array}$ & 13,498 & DM: $9.3 \%, \mathrm{DBT} \& \mathrm{DM} 6.4 \%[\mathrm{Y}]$ & DM: 5.4, DBT\&DM: $4.6[\mathrm{Y}]$ \\
\hline Margolies et al & 2014 & Hologic & 996 & DBT decreased it by $8-25 \%$ & DBT increased it by $20 \%$ \\
\hline McCarthy et al & 2015 & Hologic & $|5,57|$ & DM: $10.4 \%$, DM\&DBT: $8.8 \%[Y]$ & $\begin{array}{l}\text { DM: 4.6, DM\&DBT: } 5.5[\mathrm{~N}] \text { (extra } 0.9 \text { per } 1000 \\
\text { exams), For women under } 50 \text { yrs old: } 5.7 \text { vs } 2.2[\mathrm{Y}]\end{array}$ \\
\hline McDonald et al & 2016 & & 23958 & DM: $10.4 \%, \mathrm{DBT}: 8.8 \%[\mathrm{Y}]$ & - \\
\hline Pan et al & 2018 & Hologic & $\begin{array}{l}\text { Non- } \\
\text { specified }\end{array}$ & DM: $11.4-12.2 \%$, DM\&DBT: $9.0-10.1 \%$ & DM: 6.3-8.I, DM\&DBT: 8.5-II.4 \\
\hline Pattacini et al & 2018 & GE & 19,560 & DM\&DBT: $3.5 \%$, DM: $3.5 \%[\mathrm{~N}]$ & DM: 4.5, DM\&DBT:8.6 [Y] \\
\hline Poplack et al & 2007 & Hologic & $\begin{array}{l}99 \\
\text { (recalls) }\end{array}$ & $52 \%$ decrease with DBT & - \\
\hline Powell et al & 2016 & Hologic & $|2,78|$ & DM: $16 \%$, DM\&DBT: $14 \%[Y]$ & DM: 5.2, DBT\&DM: $7.8[\mathrm{~N}]$ \\
\hline Rafferty et al & 2013 & Hologic & 1192 & Sig. reduction with DBT & - \\
\hline Rose et al & 2013 & Hologic & 23,355 & DM: 8.7\%, DM\&DBT: $5.5 \%[\mathrm{Y}]$ & DM: 4.0, DM\&DBT: 5.4 [N] \\
\hline Rose et al & 2014 & Hologic & 10,878 & DM: $8.88 \%$, DM\&DBT: $5.41 \%[Y]$ & $55 \%$ increase with DBT \\
\hline Rose et $\mathrm{al}^{\mathrm{c}}$ & 2018 & Hologic & 59,921 & DM: II.7\%, DM\&DBT: $10.9 \%[Y]$ & DM: I.9, DM\&DBT: 2.7 [Y] \\
\hline Sharpe et al & 2016 & Hologic & 85,852 & DM: $7.51 \%$, DBT: $6.10 \%[Y]$ & - \\
\hline Singla et al & 2018 & Hologic & 100 & - & DM: $7.3 \%$, DM\&DBT: $14.6 \%[\mathrm{~N}]$ \\
\hline Skaane et al & 2012 & Hologic & 129 & - & $\begin{array}{l}4 / 84 \text { women dismissed with DM, found suspicious } \\
\text { with DBT }\end{array}$ \\
\hline Skaane et $a^{b}$ & 2013 & Hologic & $|2,63|$ & - & DM: 6.I, DM\&DBT: $8.0[Y]$ \\
\hline Skaane et al & 2018 & Hologic & 84,178 & DM: 6.7, DM\&DBT: $3.6[Y]$ & DM: 6.3, DM\&DBT: 9.3 [Y] \\
\hline Skaane et $\mathrm{al}^{\mathrm{a}}$ & 2013 & Hologic & $|2,62|$ & - & DM: 7.I, DBT\&DM: 9.4 [Y] \\
\hline Sumkin et al & 2015 & Hologic & 1074 & DM: 38.4\%, DM\&DBT: $25.5 \%$ [Y] & - \\
\hline $\begin{array}{l}\text { Thomassin- } \\
\text { Naggara et al }\end{array}$ & 2015 & Hologic & 155 & - & - \\
\hline Upadhyay et al & 2018 & Hologic & 880 & DM: I7.4\%, DM\&DBT: II.4\% [Y] & - \\
\hline
\end{tabular}

Notes: afalse positive recall; ${ }^{b}$ BIRADS3; ${ }^{c}<50$ years old.

in recall rate when DBT is added to recall of 1.5-3.4\% (median 2.75\%) among radiologists DM. ${ }^{7,34,38,39,42,47,48,56-76}$ In all cases in which statistical significance information is provided, the decrease in recall rate is significant. Only one study was found to disagree, ${ }^{43}$ in which an increased false positive for the DM\&DBT compared to $1.2 \%-2.7 \%$ (median $2.25 \%)$ for DM was found.

Lourenco et al (2015) carried out a study with 12,577 DM examinations acquired on GE systems and 921 
DM\&DBT examinations acquired on Hologic systems; a study where the comparison of DM and DBT was not done on systems of the same manufacturer though. ${ }^{77}$

With regards to studies on other manufacturers, one study on Giotto (Giotto, IMS, Italy) concluded in a significant decrease in recall rate with the addition of DBT to $\mathrm{DM},{ }^{78}$ while a study using the GE system showed no difference in the recall rate between the two imaging systems. ${ }^{79}$

\section{Cancer detection rate}

A number of studies in which Hologic systems are used to detect cancer agree that there is an increase in detection rate with the addition of DBT to DM; however, there is a conflict on whether this increase is significant. $37,38,42,43,47,48,57-61$, 63-68,70,71,75-77,80 Specifically, for ductal carcinoma in situ (an entity often presenting as microcalcifications), a significant difference was found in favor of DM\&DBT versus DM alone. $^{65}$

In studies using the GE system a significantly higher cancer detection rate was found for DBT\&DM compared to DM alone by two studies. ${ }^{77,79}$

\section{Summary}

There is a strong agreement in most of the above studies in that Hologic DM\&DBT significantly outperforms DM alone in terms of specificity and recall rate. For GE, there are only a limited number of studies completed, which show that the addition of DBT to DM increases sensitivity and specificity, as well as cancer detection rate. In a single study with Fujifilm, DM\&DBT was found to be advantageous over DM alone due to the higher AUC. Finally, Giotto's recall rate decreased in one study with the addition of DBT to DM.

It has not been adequately explored yet whether the benefit of the addition of DBT to screening outweighs the risk of additional radiation dose and whether DBT increases prevention of breast cancer deaths. There are though some new emerging studies on the assessment of interval cancers, whose data can predict the effect of DBT on the effectiveness of screening in preventing breast cancer deaths. ${ }^{7}$

\section{Single view digital breast tomosynthesis versus digital mammography}

As discussed in sections "Digital breast tomosynthesis alone versus digital mammography" and "Digital breast tomosynthesis with digital mammography versus digital mammography", for some manufacturers both DBT and DM might be necessary, mainly due to the possible superiority of DM in microcalcification detection and characterization, and the increased specificity and recall rate provided by DBT. Other more practical reasons of "not letting DM go" might include the comparisons with prior mammograms (that were also acquired with DM), the extra confidence it adds to diagnosis, as well as the "ease of using what is known". However, as discussed above, using both modalities, more than doubles the dose to the healthy woman who attends screening, ${ }^{6,14}$ as well as the reading time and the essential storage capacity. Thus, with the on-going evolution of DBT, several research groups had the idea to investigate the introduction of a 1vDBT into breast cancer screening, in addition to $1 \mathrm{vDM}$ or 2vDM (Tables 5 and 6) or alone, with the aim of keeping the dose levels lower than in the DM\&DBT option. In this section these studies are discussed for different manufacturers and different single-view techniques.

\section{Sensitivity}

Studies with Hologic systems showed a significant increase in sensitivity with the addition of one or two views of DBT to DM. ${ }^{39,81,82}$ For patients with abnormal mammograms, 1vDBT has higher sensitivity than DM, but a lower sensitivity than DM\&DBT, for patients with fatty and dense breasts. ${ }^{83}$

1vDBT (higher dose than normal 1vDBT dose) using the Siemens Mammomat Novation system and the Siemens Inspiration DBT system (Malmö, a populationbased screening programme in Sweden) was compared to $\mathrm{DM}^{84,85}$ An increase of $15 \%$ in sensitivity with $1 \mathrm{vDBT}$ compared to DM was reported. ${ }^{85}$ It is worth noting that out of the 67 lesions detected (in 7500 participants), only seven were microcalcifications, of which, one was missed by $1 \mathrm{vDBT}$, but detected by DM. A potentially worse performance for microcalcifications by 1vDBT than by $\mathrm{DM}$ at the same dose, and the opposite for masses, was found in a simulation study for Mammomat Novation. ${ }^{86}$

Using a Mammomat Siemens Inspiration it was shown that 1vDBT (MLO) does not have a statistically significant difference in sensitivity when compared with: (i) DM\&DBT; (ii) DM; (iii) 1vDM\&1vDBT. ${ }^{9}$ Similar results were found for soft tissue mammographic abnormalities separately. ${ }^{87}$ Other studies ${ }^{88,89}$ found that 1vDBT has higher sensitivity compared to DM.

Gennaro et $\mathrm{al}^{90}$ in a study with 200 women explored the clinical performance of 1vDBT (MLO) compared to DM by GE; a lower sensitivity was found for 1vDBT. On the contrary, in different retrospective studies 1vDBT was found to outperform DM. ${ }^{91}$ A study ${ }^{92}$ with 463 participants, investigated a 
Table 5 Sensitivity, specificity and AUC - comparison of IvDBT with/without IvDM or 2vDM and/or IvSM, to 2vDM

\begin{tabular}{|c|c|c|c|c|c|c|}
\hline Author & Year & Vendor & $\mathbf{N}$ & Sensitivity & Specificity & AUC \\
\hline Chae et al & 2016 & GE & 319 & $\begin{array}{l}\text { DM: } 80.7 \% \text {, IvDBT: } 88.7 \% \\
{[Y]}\end{array}$ & $\begin{array}{l}\text { DM: } 93.2 \%, \text { IvDBT: } 94.1 \% \\
{[N]}\end{array}$ & DM: 0.93, IvDBT: $0.96[Y]$ \\
\hline Gennaro et al & 2010 & GE & 200 & $\begin{array}{l}\text { DM: } 74.3 \% \text {, IvDBT: } 69.8 \% \\
{[N]}\end{array}$ & $\begin{array}{l}\text { DM: } 84.8 \%, \text { IvDBT: } 88.9 \% \\
{[N]}\end{array}$ & DM: 0.84, IvDBT: $0.85[\mathrm{~N}]$ \\
\hline Gennaro et al & 2013 & GE & 463 & $\begin{array}{l}\text { DM: } 60.0 \%, \\
\text { IvDM\&IvDBT: } 66.5 \%[Y]\end{array}$ & - & - \\
\hline Gennaro et al & 2013 & GE & 250 & $\begin{array}{l}\text { DM: } 72.8 \%, \text { DM\&IvDBT: } \\
76.2 \%[\mathrm{~N}]\end{array}$ & $\begin{array}{l}\text { DM: } 83.0 \% \\
\text { DM\&IVDBT:84.9\% [N] }\end{array}$ & - \\
\hline Heywang-Kobrunner et al & 2018 & Siemens & 285 & $\begin{array}{l}\text { DM: } 90.9 \%, \\
\text { DM\&IvDBT:96.4\%, } \\
\text { IvDBT:96.4\% [N] }\end{array}$ & $\begin{array}{l}\text { DM: } 42.2 \%, \text { DM\&IvDBT: } \\
54.3 \% \text {, IvDBT: } 56.6 \%[Y]\end{array}$ & - \\
\hline Kang et al & 2016 & GE & 130 & $\begin{array}{l}\text { DM: 73\%, IvDM\&IvDBT: } \\
\text { 69\%, IvSM\&IvDBT: } 83 \% \text {, } \\
\text { IvDM\&IvDBT\&IvSM: } \\
82 \%\end{array}$ & $\begin{array}{l}\text { DM: 90\%, IvDM\&IvDBT: } \\
\text { 95\%, IvSM\&IvDBT: } 94 \% \text {, } \\
\text { IvDM\&IvDBT\&IvSM: } \\
95 \%\end{array}$ & $\begin{array}{l}\text { DM: } 0.88 \text { I, IvDM\&IvSM: } \\
0.848, \text { IvDM\&IvDBT: } \\
0.9 \mid 4 \text {, } \\
\text { IvDM\&IvDBT\&IvSM: } \\
0.907\end{array}$ \\
\hline Lang et al & 2016 & Siemens & 7500 & $\begin{array}{l}\text { IvDBT: I5\% higher than } \\
\text { DM }\end{array}$ & - & \\
\hline Rafferty et al & 2014 & Hologic & 1192 & $\begin{array}{l}\text { DM: } 62.7 \%, \text { IvDBT: } \\
71.4 \%, \text { DBT: } 78.7 \%[Y]\end{array}$ & $\begin{array}{l}\text { DM: } 86.2 \%, \text { IvDBT: } \\
86.0 \%, \text { DBT: } 84.5 \%[\mathrm{~N}]\end{array}$ & $\begin{array}{l}\text { DM: } 0.828, \text { IvDBT: } 0.864, \\
\text { DBT: } 0.895[Y]\end{array}$ \\
\hline Rodrigyez-Ruiz et al & 2018 & Siemens & $|8|$ & $\begin{array}{l}\text { DM: } 76 \%, \text { IvDBT: } 72 \% \text {, } \\
\text { IvDM\&IvDBT: } 75 \% \\
\text { DM\&DBT: } 76 \%[N]\end{array}$ & $\begin{array}{l}\text { DM: } 76 \%, \text { IvDBT: } 74 \% \text {, } \\
\text { IvDM\&IVDBT: } 72 \% \text {, } \\
\text { DBT\&DM:73\% [N] }\end{array}$ & $\begin{array}{l}\text { DM: } 0.763, \text { IvDBT: } 0.76 \mathrm{I} \\
\text { IvDM\&IvDBT: } 0.772, \\
\text { DBT\&DM:0.782 [N] }\end{array}$ \\
\hline Shin et al & 2015 & Hologic & 149 & $\begin{array}{l}\text { DM: } 82.4 \% \\
\text { IvDM\&IvDBT:89.5\% [Y] }\end{array}$ & $\begin{array}{l}\text { DM: } 78.5 \% \\
\text { IvDM\&IvDBT: } 75.1 \%[\mathrm{~N}]\end{array}$ & $\begin{array}{l}\text { DM: } 0.869, \text { IvDM\&IvDBT: } \\
0.911 \text { [Y] }\end{array}$ \\
\hline Svahn et al & 2010 & Siemens & 50 & - & - & $\begin{array}{l}\text { DM: } 0.705, \text { IvDBT: } 0.77 \mid \\
\text { IvDM\&IvDBT: } 0.8 \mid 8[\mathrm{~N}]\end{array}$ \\
\hline Svahn et al & 2012 & Siemens & 184 & DM: 78.9\%, IvDBT: 89.7\% & DM: $55.2 \%$, IvDBT: $54.4 \%$ & $\begin{array}{l}\text { DM: } 0.706, \text { DM\&IVDBT: } \\
0.809\end{array}$ \\
\hline Thomassin-Naggara et al & 2017 & Hologic & 155 & $\begin{array}{l}\text { DM: } 72.9 \%, \text { DM\&IvDBT: } \\
89.3 \%\end{array}$ & $\begin{array}{l}\text { DM: } 50.5 \%, \text { DM\&IvDBT: } \\
50.7 \%\end{array}$ & DM: $0.685, \mathrm{DBT}: 0.809$ \\
\hline Waldherr et al & 2013 & Hologic & 144 & $\begin{array}{l}\text { DM: } 74.4 \% \text {, IvDBT: } 88.4 \% \text {, } \\
\text { DM\&DBT: } 91.9 \%\end{array}$ & $\begin{array}{l}\text { DM:76.8\%, IvDBT: } 78.9 \% \\
\text { DM\&DBT: } 75.4 \%\end{array}$ & - \\
\hline Whelehan et al & 2017 & Siemens & 238 & $\begin{array}{l}\text { DM\&IvDBT: } 90 \% \text {, } \\
\text { DM\&supplementary } \\
\text { views: } 86 \%[\mathrm{~N}]\end{array}$ & $\begin{array}{l}\text { DM\&IvDBT:59\%, } \\
\text { DM\&supplementary } \\
\text { views: } 64 \%[Y]\end{array}$ & $\begin{array}{l}\text { DM\&IvDBT:0.870, } \\
\text { DM\&SM: } 0.857[\mathrm{~N}]\end{array}$ \\
\hline Zackrison et al & 2018 & Siemens & 21,688 & DM: $60.4 \%$, IvDBT: $81.1 \%$ & DM: $98.1 \%$, IvDBT: $97.2 \%$ & - \\
\hline
\end{tabular}

Notes: $[\mathrm{Y}]=$ statistically significant, $[\mathrm{N}]=$ non-statistically significant, where available.

Table 6 Recall rate and cancer detection rate - comparison of IvDBT with/without IvDM or 2vDM and/or IvSM, to 2vDM

\begin{tabular}{|c|c|c|c|c|c|}
\hline Author & Year & Vendor & $\mathbf{N}$ & Recall rate & $\begin{array}{l}\text { Cancer detection rate } \\
{[/ 1000]}\end{array}$ \\
\hline Rafferty et al & 2014 & Hologic & 1192 & DM: $44.2 \%$, IvDBT: $27.2 \%$, DBT: $24 . \%$ [Y] & - \\
\hline Lang et al & 2016 & Siemens & 7500 & DM: $2.6 \%$, IvDBT: $3.8 \%$ & DM: 6.3, IvDBT: 8.9 \\
\hline Kang et al & 2016 & GE & 130 & $\begin{array}{l}\text { DM: } 23 \% \text {, IvDM\&IvSM: } 20 \% \text {, IvDM\&IvDBT: } 13 \% \text {, } \\
\text { IvDM\&IvDBT\&IvSM: I } 2 \%\end{array}$ & - \\
\hline Zackrison et al & 2018 & Siemens & 21,688 & - & DM: 6.5 , IvDBT: 8.7 \\
\hline
\end{tabular}

Notes: $[\mathrm{Y}]=$ statistically significant, $[\mathrm{N}]=$ non-statistically significant, where available.

different combination of views: 1vDM\&1vDBT compared to

DM alone; a significant increase was found in lesion detection with 1vDM\&1vDBT. Finally, in a more recent study of different single-view and double-view implementations methods 
of GE, it was found that the combined use of CC-DM plus MLO-DBT with SM has a higher sensitivity than DM alone. ${ }^{93}$ The GE studies on 1VDBT alone or with DM, have shown that its sensitivity is non-inferior to DM.

\section{Specificity}

Regarding Hologic, a non-significant increase in specificity with the addition of one or two views of DBT was shown. ${ }^{39,81}$

$1 \mathrm{vDBT}$ by Mammomat Novation Siemens was compared to $\mathrm{DM} ;{ }^{84}$ no difference in specificity was found by $1 \mathrm{vDBT}$ compared to DM. Rodriguez-Ruiz et $\mathrm{al}^{9}$ using 1vDBT (MLO) did not find a statistically significant difference in specificity when comparing it with: (i) DM\&DBT; (ii) DM; (iii) $1 \mathrm{vDM} \& 1 \mathrm{vDBT}$. Similarly, Zackrisson et $\mathrm{a}^{88}$ found that 1vDBT has a slightly lower specificity compared to DM, while a significant difference in specificity was found in favour of 1vDBT over supplementary mammography views, for soft tissue mammographic abnormalities. ${ }^{87}$

A non-significant difference was found in the specificity of $1 \mathrm{vDM} \& 1 \mathrm{vDBT}^{90}$ or $1 \mathrm{vDBT}^{91,92}$ compared to DM alone for GE. However, specificity for benign lesions was found to be significantly higher with the combination of single views of the two techniques, compared to DM alone. As in the case of sensitivity, specificity was also found to increase with the combined use of CC-DM plus MLO-DBT with SM compared to DM. ${ }^{93}$

\section{AUC}

For Hologic, Rafferty et al, ${ }^{81}$ showed that the AUCs were $0.828,0.864$, and 0.895 for DM, DM\&1vDBT, and DM\&DBT, respectively. The addition of one view or two views of DBT to DM resulted in a significant difference in diagnostic accuracy compared with DM alone. Compared with DM, the AUC increased by $0.036(p=0.009)$ with the addition of 1vDBT and increased by $0.068(p<0.001)$ with the addition of DBT; however, this difference did not meet their criterion of statistical significance $(p<0.0167)$. For the same manufacturer, Thomassin-Naggara et $\mathrm{al}^{39}$ and Shin et $\mathrm{al}^{82}$ showed that adding $1 \mathrm{vDBT}$ and $2 \mathrm{vDBT}$ respectively to $\mathrm{DM}$ improves the AUC, in comparison to DM alone.

$1 \mathrm{vDBT}$ by Siemens Mammomat Novation was compared to DM and a higher diagnostic accuracy (ROC and JAFROC AUC) was found for 1vDBT compared to $\mathrm{DM}^{84}$ On the contrary other studies showed a non-significant increase in AUC if 1vDBT or CC-DM with MLO-DBT are used instead of DM. ${ }^{9,94}$ In the Whelehan et $\mathrm{al}^{87}$ study, standard DM screening with additional supplementary views was found to have equivalent diagnostic accuracy in screen-detected soft tissue mammographic abnormalities and a non- significant difference in AUC of ROC analysis when compared to standard DM screening with 1vDBT.

There are conflicting conclusions on whether the difference in AUC by DM and 1vDBT by General Electric (GE) Senograph DS system is significant. ${ }^{91,92}$ In both of the above studies though, there was an increase in AUC when 1vDBT was used instead of DM, showing that $1 \mathrm{vDBT}$ is at least noninferior to DM. In a comparison of DM to $1 \mathrm{vDBT} \& \mathrm{DM},{ }^{90}$ no significant difference in AUC was found.

\section{Recall rate}

Rafferty et $\mathrm{al}^{81}$ used the Hologic system and showed that the addition of one-view or two-view DBT to DM resulted in significant reductions in recall rates, compared to DM alone. Additionally, DM with DBT also resulted in a significant reduction in recall rates compared with DM with DBT.

For Siemens Inspiration, results of the Malmö breast tomosynthesis screening trial ${ }^{85}$ demonstrated a significant increase in recall rate $(46 \%)$ when using $1 \mathrm{vDBT}$. However, the absolute increase in recall rate was actually very low (from $2.6 \%$ to $3.8 \%)$.

Finally, for GE, a significantly lower recall rate was found when using 1vDBT\&1vDM compared to DM. ${ }^{93}$

\section{Cancer detection rate}

In the Malmö trial, using Siemens systems, the detection rate for $1 \mathrm{vDBT}$ was $8.9 / 1000$ screens and for DM it was $6.3 / 1000$ (significantly different); a $40 \%$ increase in cancer detection rate using DBT alone compared to DM. Zackirson et al also showed that there is an increased cancer detection rate using $1 \mathrm{vDBT}$ versus $\mathrm{DM}^{88}$

\section{Summary}

The performance of a 1vDBT (and in some cases 1vSM too) in addition to single- or double-view DM is manufacturer dependent. Three studies that used Hologic systems show that the addition of a second view of DBT, to $2 \mathrm{vDM}$, significantly improves the recall rate and increases but not necessarily significantly the sensitivity and AUC. The manufacturer does recommend using both views of DM and DBT (Hologic, Spring 2015). The GE studies using singleview combinations of DBT alone or with DM, have shown that its sensitivity is non-inferior to DM. A recent study also shows that it might be worth considering the use of 1vDBT\&1vDM\&1vSM, as it can increase sensitivity significantly. With regards to the use of 1vDBT of Siemens, provided the user has appropriate training, it has been concluded in several studies that 1vDBT is not inferior to DM. 


\section{Digital breast tomosynthesis with synthetic mammography versus digital mammography}

To overcome the disadvantage of additional dose when using DM\&DBT, a synthetic 2D image (SM), which adds no extra dose, could be used with DBT instead. SM has completely replaced DM in some institutions; however, it might be fair to say that not all radiologists are fully convinced yet. There is ongoing work by several groups for its assessment and incorporation into the screening system worldwide. Tables 7 and 8 and this section summarize these studies.

\section{Sensitivity}

Lower sensitivity was observed with Hologic SM (known as C-view in the Hologic system) versus DM, both combined with DBT. ${ }^{95}$ Specifically, sixteen microcalcifications were missed or mis-interpreted using SM, while they were not missed with DM. However, this study was performed, before the Food and Drug Administration (FDA) approved Hologic SM to be used in combination with DBT in May 2013.

After the FDA approval, Choi et al directly compared DM (with double reading) to SM imaging and found comparable results in terms of sensitivity, specifically for T1-stage invasive breast cancers. ${ }^{96}$ The TOMMY trial, with 7060 participants, has shown an overall sensitivity of $87 \%$ for DM alone, and $88 \%$ for DBT\&SM, ie not a significant difference between the two. ${ }^{45,51}$ Similar results were found specifically for microcalcifications. ${ }^{97,98}$ In two other studies a different there was an increased sensitivity by SM and DBT\&SM compared to DM alone. ${ }^{43,44}$

Most of the above studies for Hologic SM have shown a non-significant difference in sensitivity between SM or SM with DBT versus DM or DM with DBT, even though one of them concluded that SM outperforms DM.

\section{Specificity}

A comparable specificity was observed with Hologic SM versus DM when either is combined with DBT, in the study by Gur et al before the FDA approval. ${ }^{95}$ Choi et al found comparable results, specifically for T1-stage invasive breast cancers. ${ }^{96}$ In the TOMMY trial a significant increase in specificity for DBT\&SM versus DM was found. Specificity was shown to be lower for microcalcifications and higher for distortions. ${ }^{45}$ In more recent studies, a similar specificity between SM and DM, with or without DBT, was found. ${ }^{4,97,98}$ In conclusion, specificity was shown to be at least equivalent for Hologic DM and SM, and higher for DBT\&SM when compared to DM alone.

AUC

In terms of AUC, Zuley et al (2014) showed that Hologic $\mathrm{SM}$ alone or in combination with DBT is comparable to DM alone or in combination with DBT. Similarly, for microcalcifications, the comparison of DBT\&SM versus DM\&DBT versus SM versus DM concluded in a nonsignificant difference in AUC amongst the above methods. $^{97}$ The direct comparison between DM and SM

Table 7 Sensitivity, specificity and AUC - comparison of DBT\&SM or SM to DM or of SM to DM

\begin{tabular}{|c|c|c|c|c|c|c|}
\hline Author & Year & Vendor & $\mathbf{N}$ & Sensitivity & Specificity & AUC \\
\hline Berbardi et al & 2018 & Hologic & 9672 & $\begin{array}{l}\text { SM: } 56 \text {-76\%, DBT\&SM: } 67-88 \%, \text { DM: } 46- \\
100 \%\end{array}$ & - & - \\
\hline Choi et $\mathrm{al}^{\mathrm{a}}$ & 2016 & Hologic & 214 & SM:62.6-7I\%, DM: $60.7-71.0 \%[\mathrm{~N}]$ & $\begin{array}{l}\text { SM: 84.I-96.3\%, DM: 72.9- } \\
94.4 \%[\mathrm{~N}]\end{array}$ & - \\
\hline Choi et $\mathrm{al}^{\mathrm{b}}$ & 2018 & Hologic & 198 & $\begin{array}{l}\text { SM\&DBT: } 85.6 \%-95.6 \%, \text { DM\&DBT: } 87.8- \\
94.4 \% \text {, SM: } 84.4-90 \%, \text { DM: } 78.9-88.9 \%\end{array}$ & $\begin{array}{l}\text { SM\&DBT: } 100 \%, \text { DM\&DBT: } \\
100 \%, \text { SM: } 100 \%, \text { DM: } 100 \%\end{array}$ & {$[N]$} \\
\hline Garayoa et al & 2018 & Hologic & 244 & DM: $79 \%, S M: 75 \%[N]$ & DM: $81 \%$, SM: $86 \%[N]$ & $\begin{array}{l}\text { DM: } 0.87 \\
\text { SM:0.85 [N] }\end{array}$ \\
\hline Gillbert et al & 2015 & Hologic & 7060 & DM: $87 \%$, DBT\&SM: $88 \%$ [N] & DM: 58\%, DBT\&SM: $71 \%[Y]$ & $\begin{array}{l}\text { DM: } 0.84 \\
\text { DBT\&SM: } 0.87\end{array}$ \\
\hline Gur et al & 2012 & Hologic & 114 & DM\&DBT: $82.6 \%$, DBT\&SM: $77.2 \%$ & $\begin{array}{l}\text { DM\&DBT comparable to } \\
\text { DBT\&SM }\end{array}$ & - \\
\hline Mariscotti et al & 2017 & Hologic & 231 & SM: 92\%, DM: $87 \%[Y]$ & SM: $60 \%$, DM: $62 \%[\mathrm{~N}]$ & - \\
\hline Zuley et al & 2014 & Hologic & 123 & - & - & $\begin{array}{l}\text { DM\&DBT: } 0.92 \text {, } \\
\text { DBT\&SM: } 0.94\end{array}$ \\
\hline
\end{tabular}

Notes: ${ }^{a} \mathrm{TI}$-stage invasive; ${ }^{\mathrm{b}}$ Microcalcifications. $[\mathrm{Y}]=$ statistically significant, $[\mathrm{N}]=$ non-statistically significant, where available. 
Table 8 Recall rate and cancer detection rate - comparison of DBT\&SM or SM to DM or of SM to DM

\begin{tabular}{|c|c|c|c|c|c|}
\hline Author & Year & Vendor & $\mathbf{N}$ & Recall rate & Cancer detection rate $[/ 1000]$ \\
\hline Ambinder et al & 2018 & Hologic & 22,621 & DBT\&SM: 7.06\%, DM\&DBT: $7.63 \%[Y]$ & DM\&DBT: 5.25, DBT\&SM: 5.57 [N] \\
\hline Aujero et al & 2017 & Hologic & 78,810 & $\begin{array}{l}\text { DBT\&SM: 4.3\%, DM\&DBT: 5.8\% [Y], DM: } \\
8.7 \%[Y]\end{array}$ & DM: 5.3, DM\&DBT: 6.4, DBT\&SM: $6.1[\mathrm{~N}]$ \\
\hline Berbardi et al & 2018 & Hologic & 9672 & $\begin{array}{l}\text { DM: I.2-2.7\%, SM: } 1.6-4.6 \% \text {, DBT\&SM: I.8- } \\
6.7 \%\end{array}$ & - \\
\hline Bernardi et $\mathrm{al}^{\mathrm{a}}$ & 2016 & Hologic & 9672 & $\begin{array}{l}\text { DM: } 3.4 \%, \text { DBT\&SM: } 4.0 \%, \text { DBT\&SM: } 4.5 \% \\
{[Y]}\end{array}$ & DM: 6.3, DM\&DBT: 8.5, DBT\&SM: $8.8[Y]$ \\
\hline Caumo et al & 2018 & Hologic & 34,071 & - & DM: 9.3, DBT\&SM: 5.4I [Y] \\
\hline Caumo et $\mathrm{al}^{\mathrm{a}}$ & 2018 & Hologic & 31,089 & DM: $4.2 \%$, DM\&DBT: $4.0 \%$ & DBT\&SM: 9.3, DM: 5.4I [Y] \\
\hline Freer et al & 2017 & Hologic & 31,979 & $\begin{array}{l}\text { DBT\&SM: 5.52\%, DM: } 7.83 \%[Y], \text { DM\&DBT: } \\
6.39 \%[N]\end{array}$ & DM\&DBT: 6.9, DBT\&SM: 5.9, DM: 5.9 \\
\hline Gur et al & 2012 & Hologic & 114 & $\begin{array}{l}\text { DM\&DBT: } 29.8 \% \text {, DBT\&SM: } 29.7 \% \text { (for } \\
\text { benign or no abnormality) }\end{array}$ & $\begin{array}{l}\text { Sixteen calcification clusters missed by all } \\
\text { readers with DBT\&SM }\end{array}$ \\
\hline Hofvind et al & 2018 & Hologic & 98,927 & DBT\&SM: $3.4 \%$, DM: $3.3 \%[\mathrm{~N}]$ & DBT\&SM: 9.4, SM: 6.1 [Y] \\
\hline Martin et al & 2018 & Hologic & 16,067 & $\begin{array}{l}\text { DM (double reading): } 5 \% \text {, DM\&DBT\&SM: } \\
2.8 \% \text { (single reading), DBT\&SM: } 2.9 \%[\mathrm{~N}]\end{array}$ & $\begin{array}{l}\text { DM (double reading): } 4.7 \% \text {, DM\&DBT: } 5.4 \% \text {, } \\
\text { DM\&DBT\&SM: } 5 \% \text { (single reading) }[Y]\end{array}$ \\
\hline Skaane et al & 2014 & Hologic & 24,901 & - & DM\&DBT: 7.8, DBT\&SM: 7.7 \\
\hline Zuckerman et al & 2016 & Hologic & $|5,57|$ & DBT\&SM:7.1\%, DM\&DBT: $8.8 \%[Y]$ & DBT\&SM: 5.03, DM\&DBT: $5.45[Y]$ \\
\hline Zuley et al & 2014 & Hologic & 123 & $\begin{array}{l}\text { DM: 90\%, DM\&DBT: } 93 \%, \text { DBT\&SM: } 95 \% \\
{[N]}\end{array}$ & - \\
\hline
\end{tabular}

Notes: ${ }^{a}$ False positive recall. $[\mathrm{Y}]=$ statistically significant, $[\mathrm{N}]=$ non-statistically significant, where available.

has shown a non-statistically significant difference in the AUC of the two systems. ${ }^{98}$

\section{Recall rate}

Early studies on Hologic SM have found similar recall rates for DM\&DBT, DBT\&SM, ${ }^{95,99}$ as well as DM and SM alone. ${ }^{99}$ Later studies, with a high number of participants (9672 and 15,571 respectively) have also shown an at least equivalent recall rate ${ }^{100-103}$ in DBT\&SM versus DM\&DBT, if not higher. ${ }^{104}$ Significant differences in false positive recall rate when using DM alone versus DBT\&SM, were found. ${ }^{100}$

Bernardi et al $2018^{43}$ showed an increased false positive recall rate when using DBT\&SM or SM alone, when compared to using DM alone. Sequential screen reading and the radiologists' inexperience with synthetic imaging are discussed in this study as partly explaining why an increment in false positive recall rate was documented.

Freer et $\mathrm{al}^{105}$ found a significantly lower recall rate with DBT\&SM compared to DM alone. Other studies comparing Hologic DBT\&SM versus DM\&DBT also found a lower recall rate for the first modality compared to the second, ${ }^{106,107}$ claiming not just an equal, but an even better performance in terms of this metric for DBT\&SM over DM\&DBT.

\section{Cancer detection rate}

Comparable cancer detection rates were found for Hologic DM\&DBT and DBT\&SM by Skaane et $\mathrm{al}^{108}$ in a prospective study with 24,901 participants (Oslo trial). In subgroup analyses according to tumor size and presence of calcifications, percentages of detected cancers and visibility scores were not significantly different. In a retrospective study with 15,571 participants, Zuckerman et $\mathrm{al}^{104}$ found a non-significant difference in the cancer detection rate between DM\&DBT and DBT\&SM. Similar conclusions were made in other studies. ${ }^{100,106,107}$

Results have shown that cancer detection rate was significantly higher in patients screened with DBT\&SM versus DM alone in the Verona Screening Programme too. ${ }^{109}$ Similar conclusions were drawn in other studies. ${ }^{102,103,105}$

\section{Summary}

All of the above studies are for Hologic SM, therefore they should not be generalized to any SM system and do not necessarily apply to other manufacturers. It can be concluded that, except for those studies undertaken before the FDA approval of SM, all studies support that the performance of SM together with DBT is at least equal, if not greater than that of DM and/or DM\&DBT. Work is still being undertaken on the optimal utilization of SM. ${ }^{110}$ 
Training radiologists in SM, and specifically understanding the differences in the interpretation of SM images, in comparison and perhaps in parallel to DM images, might facilitate a wider acceptance of SM.

\section{Discussion}

The aim of this review was to summarise clinical observer studies on the four common implementations with which DBT is considered for being introduced in screening: (1) DBT, (2) DM\&DBT, (3) 1vDBT with or without 1vDM or 2vDM and (4) DBT\&SM. An extensive literature review was undertaken on 89 original clinical observer studies (selected among 677 DBT studies for breast cancer screening), which evaluated one or more of the following metrics: sensitivity, specificity, AUC of ROC or JAFROC analysis, recall rate and/or cancer detection rate, for the assessment of one or more of the above implementations of DBT. Studies were discussed separately for the implementation of different DBT manufacturers to help diagnostic imaging professionals understand possible different optimal uses of different DBT systems.

This review does not directly compare implementations for different manufacturers, as studies are not always comparable, even when they assess the same metrics. Furthermore, this review does not present a head to head comparison of different manufacturers.

Hologic DBT was shown to be non-inferior to DM in several studies. However, some studies on Hologic raise a concern on the use of DBT alone in screening as DBT demonstrates better performance in terms of specificity and DM in terms of sensitivity, especially in the detection of calcifications. One could conclude that if only one of the two imaging systems is used in breast imaging, one radiological appearance of breast cancer might be more likely to be missed. When DBT together with DM is assessed versus DM alone, results showed that Hologic DBT with DM significantly outperforms DM alone in terms of specificity and recall rate, and in some studies in terms of sensitivity too. Three studies that used Hologic systems showed that the addition of the second view of DBT, to DM, significantly improves the recall rate and increases the sensitivity and AUC (not always with statistical significance). This is in agreement with the manufacturer's recommendations of using both views of DM and DBT. ${ }^{111}$ What has not been discussed extensively, to date whether the benefit outweighs the additional risk of cancer induction due to the additional dose. Except for those studies undertaken before the FDA approval of SM, all other studies on the use of C-view support that the performance of SM together with DBT, is at least equal, if not greater than that of DM and/or DM with DBT. As a technique, SM is still in its infancy so there remains work to be done to maximize its advantages and limit its drawbacks. ${ }^{110}$ What this review has not discussed are results on the new SM product by Hologic (Intelligence 2D), in which pixel size of the final DBT, and thus SM image, is smaller than that of the older-version C-view.

For Siemens, there seems to be the agreement of an increased DBT performance, if one-view high dose (compared to one-view normal dose) view is used, in comparison to DM, provided the user has been given appropriate training. ${ }^{9}$ For the same system, an increased recall rate and cancer detection rate were found for DBT.

The GE studies using single-view DBT versus DM have shown a non-significant difference in sensitivity and specificity, while there are conflicting results for AUC and recall rate. The combination of DBT with DM was shown to increase sensitivity, specificity and cancer detection rate. A recent study also shows that it might be worth considering the use of $1 \mathrm{vDBT} \& 1 \mathrm{vDM} \& 1 \mathrm{vSM}$, as it can increase sensitivity significantly.

In the only Fujifilm study that met the inclusion criteria of this review, it was found that DM\&DBT outperforms DM alone in terms of AUC of ROC analysis. ${ }^{55}$ With regards to studies on other manufactures, one study on Giotto (Giotto, IMS, Italy) ${ }^{78}$ showed a significant decrease in recall rate with the addition of DBT to DM. Wallis et al compared single-view Sectra photon counting DM\&DBT system. $^{31}$ A statistically significant difference was found in the AUC by DM versus DBT, only for five readers less than ten years of mammography experience. A non-significant difference was found when DM was compared to 1vDBT for ten readers that had mixed levels of experience.

\section{Considerations for DBT implementation}

Based on the pool of studies used for the purposes of this review, it can be concluded that more studies have been completed for Hologic, compared to other manufacturers, especially for some of the implementation methods. For instance, for SM (section "Single view digital breast tomosynthesis versus digital mammography"), only studies involving Hologic were discussed. It is important to recognise that conclusions on implementations from different DBT 
manufactures do not necessarily apply to other manufacturers. Care should thus be taken when presenting or discussing DBT, as its optimum use might vary between different manufacturers. This is largely due to the different technical specifications of the different systems (section "This work").

For one imaging centre that is considering introducing DM and/or DBT it is important to use the right implementation based on the system that is available or will be bought. What will be bought or implemented, however, sometimes depends also on other practical, patient specific, staff training or financial factors. Therefore, care should be taken with the conclusions of original studies, as an adaptation might need to be made on the selection of the system in the particular centre.

There are other factors that can be incorporated into the methodology of the usage of an imaging implementation, and can affect the diagnostic performance of the system, that have not been addressed in this review. One of these factors is double image reading. ${ }^{112}$ As shown by Houssami et al single-reading of DBT (integrated DM\&DBT or DBT\&SM) detected more breast cancers and had a lower false positive recall rate, compared to double-reading DM alone. Similarly, the usage of prior mammograms might have an impact on the screening capabilities of a system. As shown by Kim et al, ${ }^{41}$ prior mammograms can affect the specificity of the imaging systems. In addition, as discussed above, patient specific background might affect the optimum usage of an imaging system and this has been recently assessed in a few studies. ${ }^{25,35}$ For example, the risk of cancer for a woman, which might be relevant to factors like history, age and breast density, might change the frequency and number of times a patient is screened and the implementation by which she is screened.

Finally, one interested in DBT implementation in breast cancer screening also owes to be aware of its possible drawbacks, including overdiagnosis and overtreatment. It has not been adequately explored yet whether DBT increases prevention of breast cancer deaths. There are on-going emerging studies on the assessment of interval cancers, whose data will predict the effect of DBT on the effectiveness of screening in preventing breast cancer deaths. ${ }^{7,113}$

\section{Conclusion}

Based on current knowledge, there appears to be benefit from the implementation of DBT in breast screening with or without DM and/or SM. DBT can perform at least equally to DM in most metrics and clinical scenarios; and in combination with DM and/or SM it can outperform DM, however this remains manufacturer- and metric- depended. More clinical observer studies were carried out using some DBT systems than others. For an implementation method of DBT by one manufacturer there might still be a shortage of studies, while for another implementation there might be conflicting results or even practical issues for implementation. In several cases, there is a strong agreement between studies, making the advantages and disadvantages of each system clear. The optimum implementation method, in terms of diagnostic benefit, together with the patient dose in mind, for one manufacturer does not necessarily apply to other manufacturers, due to the different technical specifications that different DBT systems have.

\section{Acknowledgment}

The authors would like to thank the University of Cyprus for providing funding for this work and the Bank of Cyprus Oncology Centre for their support. The authors acknowledge the helpful editing of the manuscript by Dr Paul Doolan.

\section{Disclosure}

The authors report no conflicts of interest in this work.

\section{References}

1. Ferlay J, Soerjomataram I, Forman D, et al. Cancer incidence and mortality worldwide: sources, methods and major patterns in GLOBOCAN 2012. Int $J$ Cancer. 2014;136(5):E359-86. doi:10.10 02/ijc. 29210

2. Shulman LN, Willett W, Sievers A, Knaul FM. Breast cancer in developing countries: opportunities for improved survival. $J$ Oncol. 2010;2010:1-6. doi:10.1155/2010/595167

3. Altobelli E, Lattanzi A. Breast cancer in European Union: an update of screening programmes as of March 2014 (Review). Int J Oncol. 2014;45(5):1785-1792. doi:10.3892/ijo.2014.2632

4. Broeders MH, Moss S, Nyström L, et al. The impact of mammographic screening on breast cancer mortality in Europe: a review of trend studies. J Med Screen. 2012;19(1):26-32. doi:10.1258/jms.2012. 012078

5. Kim Y-J, Sechopoulos I, Newell MS, et al. Comparison of two-view digital breast tomosynthesis to three-view digital mammography in a simulated screening setting. Acta Radiol. 2018;60(9)1-8.

6. Dance DR, Strudley CJ, Young KC, et al. Comparison of breast doses for digital tomosynthesis estimated from patient exposures and using PMMA breast phantoms. In: Bakic PR, Gavenonis S, editors. Breast Imaging, 11th International Workshop, IWDM 2012, ADA Maidment, LNCS 7361. Berlin, Springer-Verlag; 2012: 316-321..

7. Skaane $\mathrm{P}$, Sebuødegård S, Bandos $\mathrm{AI}$, et al. Performance of breast cancer screening using digital breast tomosynthesis: results from the prospective population-based Oslo tomosynthesis screening trial. Breast Cancer Res Treat. 2018;169(3):489-496. doi:10.1007/ s10549-018-4705-2

8. Michell MJ, Batohi B. Role of tomosynthesis in breast imaging going forward. Clin Radiol. 2018;73(4):358-371. doi:10.1016/j. crad.2018.01.001 
9. Rodriguez-Ruiz A, Gubern-Merida A, Imhof-Tas M, et al. Oneview digital breast tomosynthesis as a stand-alone modality for breast cancer detection: do we need more? Eur Radiol. 2017;28 (5):1938-1948. doi:10.1007/s00330-017-5167-3

10. Chakraborty DP. Recent advances in observer performance methodology: jackknife free-response ROC (JAFROC). Radiat Prot Dosimetry. 2005;114(1-3):26-31. doi:10.1093/rpd/nch512

11. Chakraborty DP. Validation and statistical power comparison of methods for analyzing free-response observer performance studies. Acad Radiol. 2008;15(12):1554-1566. doi:10.1016/j.acra.2008.07.018

12. Gilbert FJ, Tucker L, Young KC. Digital breast tomosynthesis (DBT): a review of the evidence for use as a screening tool. Clin Radiol. 2016;71(2):141-150. doi:10.1016/j.crad.2015.11.008

13. Mall S, Noakes J, Kossoff M, et al. Can digital breast tomosynthesis perform better than standard digital mammography work-up in breast cancer assessment clinic? Eur Radiol. 2018;28(12):51825194. doi:10.1007/s00330-018-5473-4

14. Bouwman RW, Van Engen RE, Young KC, et al. Average glandular dose in digital mammography and digital breast tomosynthesis: comparison of phantom and patient data. Phys Med Biol. 2015;60 (20):7893-7907. doi:10.1088/0031-9155/60/20/7893

15. Teertstra HJ, Loo CE, Van Den Bosch MAAJ, et al. Breast tomosynthesis in clinical practice: initial results. Eur Radiol. 2010;20 (1):16-24. doi:10.1007/s00330-009-1688-8

16. Seo M, Kim SA, Chang JM, et al. Addition of digital breast tomosynthesis to full-field digital mammography in the diagnostic setting: additional value and cancer detectability. J Breast Cancer. 2016;19(4):438. doi:10.4048/jbc.2016.19.4.438

17. Bian T, Lin Q, Cui C, et al. Digital breast tomosynthesis: a new diagnostic method for mass-like lesions in dense breasts. Breast J. 2016;22(5):535-540. doi:10.1111/tbj.12622

18. Tagliafico A, Mariscotti G, Durando M, et al. Characterisation of microcalcification clusters on 2D digital mammography (FFDM) and digital breast tomosynthesis (DBT): does DBT underestimate microcalcification clusters? Results of a multicentre study. Eur Radiol. 2015;25(1):9-14. doi:10.1007/s00330-014-3402-8

19. Spangler ML, Zuley ML, Sumkin JH, et al. Detection and classification of calcifications on digital breast tomosynthesis and 2D digital mammography: a comparison. Am J Roentgenol. 2011;196(2):320-324.

20. Hadjipanteli A, Elangovan P, Mackenzie A, Wells K, Dance DR, Young KC. The threshold detectable mass diameter for 2D-mammography and digital breast tomosynthesis. Phys Med. 2019;57 (2018):25-32. doi:10.1016/j.ejmp.2018.11.014

21. Elangovan P, Rashidnasab A, Mackenzie A, et al. Performance comparison of breast imaging modalities using a 4AFC human observer study. In: Proc. SPIE 9412, Medical Imaging 2015: Physics of Medical Imaging, $94121 \mathrm{~T}$ (18 March 2015); Orlando, FL, USA.

22. Hadjipanteli A, Elangovan P, Mackenzie A, et al. The effect of system geometry and dose on the threshold detectable calcification diameter in 2D-mammography and digital breast tomosynthesis. Phys Med Biol. 2017;62(3):858-877. doi:10.1088/1361-6560/aa4f6e

23. Mackenzie A, Marshall NW, Hadjipanteli A, Dance DR, Bosmans $\mathrm{H}$, Young KC. Characterisation of noise and sharpness of images from four digital breast tomosynthesis systems for simulation of images for virtual clinical trials. Phys Med Biol. 2017;62(6):23762397. doi:10.1088/1361-6560/aa5dd9

24. Mainprize JG, Bloomquist AK, Kempston MP, Yaffe MJ. Resolution at oblique incidence angles of a flat panel imager for breast tomosynthesis. Med Phys. 2006;33(9):3159-3164. doi:10.11 $18 / 1.2241994$

25. Li J, Zhang H, Jiang H, et al. Diagnostic performance of digital breast tomosynthesis for breast suspicious calcifications from various populations: a comparison with full-field digital mammography. Comput Struct Biotechnol J. 2018;17:82-89. doi:10.1016/j. csbj.2018.12.004
26. Dibble EH, Lourenco AP, Baird GL, Ward RC, Maynard AS, Mainiero MB. Comparison of digital mammography and digital breast tomosynthesis in the detection of architectural distortion. Eur Radiol. 2017;28(1):3-10. doi:10.1007/s00330-017-4968-8

27. Clauser P, Nagl G, Helbich TH, et al. Diagnostic performance of digital breast tomosynthesis with a wide scan angle compared to full-field digital mammography for the detection and characterization of microcalcifications. Eur J Radiol. 2016;85(12):2161-2168. doi:10.1016/j.ejrad.2016.10.004

28. Asbeutah A, Karmani N, Asbeutah A, Echreshzadehb Y, AlMajran A, Alkhalifah K. Comparison of Digital Breast Tomosynthesis (DBT) and Digital Mammography (DM) for Detection of Breast Cancer in Women in Kuwait. Med Princ Pract. 2018;28(1):10-15.

29. Brandt KR, Craig DA, Hoskins TL, et al. Can digital breast tomosynthesis replace conventional diagnostic mammography views for screening recalls without calcifications? A comparison study in a simulated clinical setting. Am J Roentgenol. 2013;200(2):291-298. doi:10.2214/AJR.12.8881

30. Good WF, Gordon AS, Victor CJ, et al. Digital breast tomosynthesis: a pilot observer study. Am J Roentgenol. 2008;190(4):865869. doi:10.2214/AJR.07.2841

31. Wallis MG, Moa E, Zanca F, Leifland K, Danielsson M. Two-View and Single-View tomosynthesis versus full-field digital mammography: high-resolution x-ray imaging observer study. Radiology. 2012;262(3):788-796. doi:10.1148/radiol.11103514

32. Giess CS, Pourjabbar S, Ip IK, Lacson R, Alper E, Khorasani R. Comparing diagnostic performance of digital breast tomosynthesis and full-field digital mammography in a hybrid screening environment. Am J Roentgenol. 2017;209(4):929-934. doi:10.2214/AJR.17.17983

33. Aase H, Holen $\AA$ S, Pedersen K, et al. A randomized controlled trial of digital breast tomosynthesis versus digital mammography in population-based screening in Bergen: interim analysis of performance indicators from the to-be trial. Eur Radiol. 2018;29 (3):1175-1186. doi:10.1007/s00330-018-5690-x

34. Gur D, Abrams GS, Chough DM, et al. Digital breast tomosynthesis: observer performance study. Am J Roentgenol. 2009;193 (2):586-591. doi:10.2214/AJR.08.2031

35. Yi A, Chang JM, Shin SU. et al. Detection of noncalcified breast cancer in patients with extremely dense breasts using digital breast tomosynthesis compared with full-field digital mammography. $\mathrm{Br} J$ Radiol.2018;20180101. doi:10.1259/bjr.20180101

36. Michell MJ, Iqbal A, Wasan RK, et al. A comparison of the accuracy of film-screen mammography, full-field digital mammography, and digital breast tomosynthesis. Clin Radiol. 2012;67 (10):976-981. doi:10.1016/j.crad.2012.03.009

37. Rafferty EA, Park JM, Philpotts LE, et al. Digital mammography and breast tomosynthesis compared with digital mammography alone: results of a multicenter, multireader trial. Radiology. 2013;266(1):104-113. doi:10.1148/radiol.12120674

38. Houssami N, Macaskill P, Bernardi D, et al. Breast screening using 2D-mammography or integrating digital breast tomosynthesis (3Dmammography) for single-reading or double-reading - evidence to guide future screening strategies. Eur J Cancer. 2014;50(10):17991807. doi:10.1016/j.ejca.2014.03.017

39. Thomassin-Naggara I, Perrot N, Dechoux S, Ribeiro C, Chopier J, de Bazelaire C. Added value of one-view breast tomosynthesis combined with digital mammography according to reader experience. Eur J Radiol. 2014;84(2):235-241. doi:10.1016/j.ejrad.2014. 10.022

40. Alakhras M, Bourne R, Rickard M, Ng KH, Pietrzyk M, Brennan PC. Digital tomosynthesis: A new future for breast imaging? Clin Radiol. 2013;68(5):e225-e236. doi:10.1016/j.crad.2013.01.007

41. Kim WH, Chang JM, Koo HR, et al. Impact of prior mammograms on combined reading of digital mammography and digital breast tomosynthesis. Acta Radiol. 2017;58(2):148-155. doi:10.1177/ 0284185116647211 
42. Singla D, Chaturvedi AK, Aggarwal A, Rao SA, Hazarika DVM. Comparing the diagnostic efficacy of full field digital mammography with digital breast tomosynthesis using BIRADS score in a tertiary cancer care hospital. Indian J Radiol Imaging. 2018;28(1):115-122.

43. Bernardi D, Li T, Pellegrini M, et al. Effect of integrating digital breast tomosynthesis (3D-mammography) with acquired or synthetic 2D-mammography on radiologists' true-positive and falsepositive detection in a population screening trial: A descriptive study. Eur J Radiol. 2018;106:26-31. doi:10.1016/j.ejrad.2018.07. 008

44. Mariscotti G, Durando M, Houssami N, et al. Comparison of synthetic mammography, reconstructed from digital breast tomosynthesis, and digital mammography: evaluation of lesion conspicuity and BI-RADS assessment categories. Breast Cancer Res Treat. 2017;166(3):765-773. doi:10.1007/s10549-017-4458-3

45. Gillbert FJ, Tucker L, Gillan MG, et al. The TOMMY trial: a comparison of TOMosynthesis with digital MammographY in the UK NHS Breast Screening Programme - a multicentre retrospective reading study comparing the diagnostic performance of digital breast tomosynthesis and digital mammography with di. Health Technol Assess (Rockv). 2015;19(4):1-136. doi:10.3310/hta19030

46. Tucker L, Gilbert FJ, Astley SM, et al. Does reader performance with digital breast tomosynthesis vary according to experience with two-dimensional mammography? Radiology. 2017;283(2):371380. doi:10.1148/radiol.2017151936

47. Conant EF, Beaber EF, Sprague BL, et al. Breast cancer screening using tomosynthesis in combination with digital mammography compared to digital mammography alone: a cohort study within the PROSPR consortium. Breast Cancer Res Treat. 2016;156 (1):109-116. doi:10.1007/s10549-016-3695-1

48. Alsheik NH, Dabbous F, Pohlman SK, et al. Comparison of resource utilization and clinical outcomes following screening with digital breast tomosynthesis versus digital mammography: findings from a learning health system. Acad Radiol. 2018;60068:1-9. doi:10.1016/j.acra.2018.05.026

49. Ohashi R, Nagao M, Nakamura I, Okamoto T, Sakai S. Improvement in diagnostic performance of breast cancer: comparison between conventional digital mammography alone and conventional mammography plus digital breast tomosynthesis. Breast Cancer. 2018;25(5):590-596. doi:10.1007/s12282-018-0859-3

50. Alakhras MM, Brennan PC, Rickard M, Bourne R, Mello-Thoms C. Effect of radiologists' experience on breast cancer detection and localization using digital breast tomosynthesis. Eur Radiol. 2014. Available from: http://www.ncbi.nlm.nih.gov/pubmed/25192796. Accessed September 25, 2014.

51. Gilbert FJ, Tucker L, Gillan MGC, et al. Accuracy of digital breast tomosynthesis for depicting breast cancer subgroups in a UK Retrospective Reading Study (TOMMY trial). Radiology. 2015;277(3):697-706. doi:10.1148/radiol.2015142566

52. Gur D, Bandos AI, Rockette HE, et al. Localized detection and classification of abnormalities on FFDM and tomosynthesis examinations rated under an FROC paradigm. Am $J$ Roentgenol. 2011;196(3):737-741. doi:10.2214/AJR.10.4760

53. Mariscotti G, Durando M, Houssami N, et al. Digital breast tomosynthesis as an adjunct to digital mammography for detecting and characterising invasive lobular cancers: a multi-reader study. Clin Radiol. 2016;71(9):889-895. doi:10.1016/j.crad.2016.04.004

54. Bansal GJ, Young P. Digital breast tomosynthesis within a symptomatic "One-stop breast clinic" for characterisation of subtle findgins. Br Inst Radiol. 2015;187(1):35-49.

55. Endo T, Morita T, Oiwa M, et al. Detectability comparison of modes in dual-mode digital breast tomosynthesis. Breast Cancer. 2016;24(3):442-450. doi:10.1007/s12282-016-0725-0

56. Durand M, Haas M, Yao X, et al. Early clinical experience with digital breast tomosynthesis for screening mammography. Radiology. 2015;274(1):85-92. doi:10.1148/radiol.14131319
57. Friedewald SM, Rafferty EA, Rose SL, et al. Breast cancer screening using tomosynthesis in combination with digital mammography. J Am Med Assoc. 2014;311(24):2499-2507. doi:10.1001/jama. 2014.6095

58. Greenberg JS, Javitt MC, Katzen J, Michael S, Holland AE. Clinical performance metrics of $3 \mathrm{D}$ digital breast tomosynthesis compared with 2D digital mammography for breast cancer screening in community practice. Am J Roentgenol. 2014;203(3):687693. doi:10.2214/AJR.14.12642

59. Haas BM, Kalra V, Geisel J, Raghu M, Durand M, Philipotts LE. Comparison of tomosynthesis plus digital mammography and digital mammography alone for breast cancer screening. $J R$ Soc Med. 2000;93(5):234-237.

60. Margolies L, Cohen A, Sonnenblick E, et al. Digital breast tomosynthesis changes management in patients seen at a tertiary care breast center. ISRN Radiol. 2014;2014:1-8. doi:10.1155/2014/658929

61. McCarthy AM, Kontos D, Synnestvedt M, et al. Screening outcomes following implementation of digital breast tomosynthesis in a general-population screening program. $J$ Natl Cancer Inst. 2014;106(11). doi:10.1093/jnci/dju061.

62. McDonald ES, Oustimov A, Weinstein SP, Synnestvedt MB, Schnall M, Conant EF. Effectiveness of digital breast tomosynthesis compared with digital mammography: outcomes analysis from 3 years of breast cancer screening. JAMA Oncol. 2016;2(6):737743. doi:10.1001/jamaoncol.2015.5778

63. Ben PH, Wong KF, Yao A, et al. Breast cancer screening with digital breast tomosynthesis - 4 year experience and comparison with national data. J Chin Med Assoc. 2018;81(1):70-80. doi:10.1016/j.jcma.2017.05.013

64. Poplack SP, Tosteson TD, Kogel CA, Nagy HM. Digital breast tomosynthesis: initial experience in 98 women. AJR Am J Roentgenol. 2007;189:616-623. doi:10.2214/AJR.07.2231

65. Powell JL, Hawley JR, Lipari AM, Yildiz VO, Erdal BS, Carkaci S. Impact of the addition of Digital Breast Tomosynthesis (DBT) to Standard 2D digital screening mammography on the rates of patient recall, cancer detection, and recommendations for short-term follow-up. Acad Radiol. 2017;24(3):302-307. doi:10.1016/j.acra.2016.10.001

66. Rose SL, Shisler JL. Tomosynthesis impact on breast cancer screening in patients younger than 50 years old. $\mathrm{Am} J$ Roentgenol. 2018;210(6):1401-1404. doi:10.2214/AJR.17.18839

67. Rose SL, Tidwell AL, Ice MF, Nordmann AS, Sexton R, Song R. A reader study comparing prospective tomosynthesis interpretations with retrospective readings of the corresponding FFDM examinations. Acad Radiol. 2014;21(9):1204-1210. doi:10.1016/j.acra.20 14.04.008

68. Rose SL, Tidwell AL, Bujnoch LJ, Kushwaha AC, Nordmann AS, Sexton R. Implementation of breast tomosynthesis in a routine screening practice: an observational study. Am $J$ Roentgenol. 2013;200(6):1401-1408. doi:10.2214/AJR.12.9672

69. Sharpe RE, Venkataraman S, Phillips J, et al. Increased cancer detection rate and variations in the recall rate resulting from implementation of 3D digital breast tomosynthesis into a populationbased screening program. Radiology. 2016;280(3):981. doi:10.11 48/radiol.2016164018

70. Skaane P, Bandos A, Gullien R, et al. Comparison of digital mammography alone and digital mammography plus tomosynthesis in a population-based screening program. Radiology. 2013;267 (1):47-56.

71. Skaane P, Bandos AI, Gullien R, et al. Prospective trial comparing full-field digital mammography (FFDM) versus combined FFDM and tomosynthesis in a population-based screening programme using independent double reading with arbitration. Eur Radiol. 2013;23(8):2061-2071. doi:10.1007/s00330-013-2820-3

72. Sumkin JH, Bandos AI, Shinde DD, et al. Recall rate reduction with tomosynthesis during baseline screening examinations. Acad Radiol. 2015;22(12):1477-1482. doi:10.1016/j.acra.2015.08.015 
73. Upadhyay N, Soneji N, Stewart V, Ralleigh G. The effect of the addition of tomosynthesis to digital mammography on reader recall rate and reader confidence in the UK prevalent screening round. Clin Radiol. 2018;73(8):744-749. doi:10.1016/j.crad.2018.03.013

74. Bahrs SD, Otto V, Hattermann V, et al. Breast tomosynthesis for the clarification of mammographic BI-RADS 3 lesions can decrease follow-up examinations and enables immediate cancer diagnosis. Acta Radiol. 2018;59(10):1176-1183. doi:10.1177/0284185118756458

75. Cohen EO, Tso HH, Mayo RC, Leung JWT. Screening mammography findings from one standard projection only in the era of fullfield digital mammography and digital breast tomosynthesis. Women's Imaging. 2018;211(2):445-451.

76. Destounis S, Morgan R, Arieno A. Initial experience with combination digital breast tomosynthesis plus full field digital mammography or full field digital mammography alone in the screening environment. J Clin Imaging Sci. 2014;4(1):9. doi:10.4103/2156-7514.127838

77. Lourenco AP, Barry-Brooks M, Baird GL, Tuttle A, Mainiero MB. Changes in recall type and patient treatment following implementation of screening digital breast tomosynthesis. Radiology. 2014;274(2):337-342. doi:10.1148/radiol.14140317

78. Carbonaro LA, Di Leo G, Clauser P, et al. Impact on the recall rate of digital breast tomosynthesis as an adjunct to digital mammography in the screening setting. A double reading experience and review of the literature. Eur $J$ Radiol. 2016;85(4):808-814. doi:10.1016/j.ejrad.2016.01.004

79. Pattacini P, Nitrosi A, Giorgi Rossi P, et al. digital mammography versus digital mammography plus tomosynthesis for breast cancer screening: the Reggio Emilia tomosynthesis randomized trial. Radiology. 2018;288(2):375-385. doi:10.1148/radiol.2018172119

80. Skaane P, Gullien R, Bjørndal H, et al. Digital breast tomosynthesis (DBT): initial experience in a clinical setting. Acta Radiol. 2012;53 (5):524-529. doi:10.1258/ar.2012.120062

81. Rafferty EA, Park JM, Philpotts LE, et al. Diagnostic accuracy and recall rates for digital mammography and digital mammography combined with one-view and two-view tomosynthesis: results of an enriched reader study. Am J Roentgenol. 2014;202(2):273-281. doi:10.2214/AJR.13.11240

82. Shin SU, Seo M, Kim WH, et al. Comparative evaluation of average glandular dose and breast cancer detection between single-view digital breast tomosynthesis (DBT) plus single-view digital mammography (DM) and two-view DM: correlation with breast thickness and density. Eur Radiol. 2014;25(1):1-8. doi:10.1007/ s00330-014-3399-z

83. Waldherr C, Cerny P, Altermatt HJ, et al. Value of one-view breast tomosynthesis versus two-view mammography in diagnostic workup of women with clinical signs and symptoms and in women recalled from screening. Am J Roentgenol. 2013;200 (1):226-231. doi:10.2214/AJR.11.8202

84. Svahn TM, Chakraborty DP, Ikeda D, et al. Breast tomosynthesis and digital mammography: A comparison of diagnostic accuracy. Br J Radiol. 2012;85:1019. doi:10.1259/bjr/53282892

85. Lång K, Andersson I, Rosso A, Tingberg A, Timberg P, Zackrisson S. Performance of one-view breast tomosynthesis as a stand-alone breast cancer screening modality: results from the Malmö breast tomosynthesis screening trial, a population-based study. Eur Radiol. 2015;26(1):184-190. doi:10.1007/s00330-015-3803-3

86. Timberg P, Båth M, Andersson I, Mattsson S, Tingberg A, Ruschin M. Visibility of microcalcification clusters and masses in breast tomosynthesis image volumes and digital mammography: A 4AFC human observer study. Med Phys. 2012;39(5):2431-2437. doi: $10.1118 / 1.3694105 \% 5 \mathrm{Cn}$

87. Whelehan $\mathrm{P}$, Heywang-Köbrunner SH, Vinnicombe SJ, et al. Clinical performance of Siemens digital breast tomosynthesis versus standard supplementary mammography for the assessment of screen-detected soft-tissue abnormalities: a multi-reader study. Clin Radiol. 2016;72(1):95.e9-95.e15. doi:10.1016/j.crad.2016.08.011
88. Zackrisson S, Lång K, Rosso A, et al. One-view breast tomosynthesis versus two-view mammography in the Malmö Breast Tomosynthesis Screening Trial (MBTST): a prospective, population-based, diagnostic accuracy study. Lancet Oncol. 2018;19 (11):1493-1503. doi:10.1016/S1470-2045(18)30144-X

89. Heywang-Köbrunner S, Jaensch A, Hacker A, Wulz-Horber S, Mertelmeier T, Hölzel D. Value of digital breast tomosynthesis versus additional views for the assessment of screen-detected abnormalities - a first analysis. Breast Care. 2017;12(2):92-97. doi:10.1159/000456649

90. Gennaro G, Toledano A, Di Maggio C, et al. Digital breast tomosynthesis versus digital mammography: a clinical performance study. Eur Radiol. 2009;20(7):1545-1553. doi:10.1007/s00330-009-1688-8

91. Chae EY, Kim HH, Cha JH, Shin HJ, Choi WJ. Detection and characterization of breast lesions in a selective diagnostic population: diagnostic accuracy study for comparison between one-view digital breast tomosynthesis and two-view full-field digital mammography. Br J Radiol. 2016;89(1062):9-13. doi:10.1259/bjr.20150743

92. Gennaro G, Hendrick RE, Toledano A, et al. Combination of one-view digital breast tomosynthesis with one-view digital mammography versus standard two-view digital mammography: per lesion analysis. Eur Radiol. 2013;23(8):2087-2094. doi:10.1007/s00330-013-2831-0

93. Kang H-J, Chang JM, Lee J, et al. Replacing single-view mediolateral oblique (MLO) digital mammography (DM) with synthesized mammography (SM) with digital breast tomosynthesis (DBT) images: comparison of the diagnostic performance and radiation dose with two-view DM with or without MLO-DB. Eur J Radiol. 2016;85(11):2042-2048. doi:10.1016/j.ejrad.2016.09.007

94. Svahn T, Andersson I, Chakraborty D, et al. The diagnostic accuracy of dual-view digital mammography, single-view breast tomosynthesis and a dual-view combination of breast tomosynthesis and digital mammography in a free-response observer performance study. Radiat Prot Dosimetry. 2010;139(1-3):113-117. doi:10.1093/rpd/ncq044

95. Gur D, Zuley ML, Anello MI, et al. Dose Reduction in Digital Breast Tomosynthesis (DBT) screening using synthetically reconstructed projection images. Acad Radiol. 2012;19(2):166-171. doi:10.1016/j.acra.2011.10.003

96. Choi JS, Han B-K, Ko EY, et al. Comparison between two-dimensional synthetic mammography reconstructed from digital breast tomosynthesis and full-field digital mammography for the detection of T1 breast cancer. Eur Radiol. 2015;26(8):2538-2546. doi:10.10 07/s00330-015-4083-7

97. Choi JS, Han BK, Ko EY, Kim GR, Ko ES, Park KW. Comparison of synthetic and digital mammography with digital breast tomosynthesis or alone for the detection and classification of microcalcifications. Eur Radiol. 2019;29(1):319-329. doi:10.1007/s00330-018-5585-x

98. Garayoa J, Chevalier M, Castillo M, et al. Diagnostic value of the stand-alone synthetic image in digital breast tomosynthesis examinations. Eur Radiol. 2017;28(2):565-572. doi:10.1007/s00330017-4991-9

99. Zuley ML, Guo B, Catullo VJ, et al. Comparison of twodimensional synthesized mammograms versus original digital mammograms alone and in combination with tomosynthesis images. Radiology. 2014;271(3):664-671. doi:10.1148/radiol.13 131530

100. Bernardi D, Macaskill P, Pellegrini M, et al. Breast cancer screening with tomosynthesis (3D mammography) with acquired or synthetic 2D mammography compared with $2 \mathrm{D}$ mammography alone (STORM-2): a population-based prospective study. Lancet Oncol. 2016;17(8):1105-1113. doi:10.1016/S1470-2045 (16)30101-2

101. Caumo F, Rella R, Brunelli S, et al. Digital breast tomosynthesis with synthesized two-dimensional images versus full-field digital mammography for population screening: outcomes from the verona screening program. Radiology. 2017;287(1):37-46. doi:10.1148/ radiol. 2017170745 
102. Hofvind S, Hovda T, ÅS H, et al. Digital breast tomosynthesis and synthetic 2D mammography versus digital mammography: evaluation in a population-based screening program. Radiology. 2018;171361. doi:10.1148/radiol.2018171361.

103. Martín SR, Povedano JLR, García MC, Romero ALS, Garriguet MP, Benito MÁ. Prospective study aiming to compare 2D mammography and tomosynthesis + synthesized mammography in terms of cancer detection and recall. From double reading of 2D mammography to single reading of tomosynthesis. Eur Radiol. 2018;28(6):2484-2491. doi:10.1007/s00330-017-5219-8

104. Zuckerman SP, Keller BM, McDonald ES, et al. Implementation of synthesized two-dimensional mammography in a population-based digital breast tomosynthesis screening program. Radiology. 2016;281(3):730-736. doi:10.1148/radiol.2016160366

105. Freer PE, Riegert J, Eisenmenger L, et al. Clinical implementation of synthesized mammography with digital breast tomosynthesis in a routine clinical practice. Breast Cancer Res Treat. 2017;166 (2):501-509. doi:10.1007/s10549-017-4431-1

106. Ambinder EB, Harvey SC, Panigrahi B, Li X, Woods RW. Synthesized mammography: the new standard of care when screening for breast cancer with digital breast tomosynthesis? Acad Radiol. 2018;25(8):973-976. doi:10.1016/j.acra.2017.12.015

107. Aujero MP, Gavenonis SC, Benjamin R, Zhang Z, Holt JS. Clinical Performance of Synthesized Two-dimensional Mammography Combined with Tomosynthesis in a Large Screening Population. Radiology. 2017;283(1):70-76. doi: 10.1148/radiol.2017162674
108. Skaane P, Bandos AI, Eben EB, et al. Two-view digital breast tomosynthesis screening with synthetically reconstructed projection images: comparison with digital breast tomosynthesis with full-field digital mammographic images. Radiology. 2014;271(3):655-663.

109. Caumo F, Romanucci G, Hunter K, et al. Comparison of breast cancers detected in the Verona screening program following transition to digital breast tomosynthesis screening with cancers detected at digital mammography screening. Breast Cancer Res Treat. 2018;170(2):391-397. doi:10.1007/s10549-018-4756-4

110. Ratanaprasatporn L, Chikarmane SA, Giess CS. Strengths and weaknesses of synthetic mammography in screening. RadioGraphics. 2017;37(7):1913-1927. doi:10.1148/rg.2017164012

111. Smith A. Hologic. Breast Tomosynthesis: The Use of Breast Tomosynthesis in a Clinical Setting; White Paper. Hologic; 2015. Available from: http://www.hologic.ca/sites/default/files/WP00060_Tomo\%20White\%20Paper_Rev5.pdf.

112. Houssami N, Bernardi D, Pellegrini M, et al. Breast cancer detection using single-reading of breast tomosynthesis (3D-mammography) compared to double-reading of 2D-mammography: evidence from a population-based trial. Cancer Epidemiol. 2017;47:94-99. doi:10.1016/j.canep.2017.01.008

113. Bernardi D, Belli P, Benelli E, et al. Digital breast tomosynthesis (DBT): recommendations from the Italian College of Breast Radiologists (ICBR) by the Italian Society of Medical Radiology (SIRM) and the Italian Group for Mammography Screening (GISMa). Radiol Med. 2017;122(10):723-730. doi:10.1007/s11547-017-0769-z

\section{Publish your work in this journal}

Cancer Management and Research is an international, peer-reviewed open access journal focusing on cancer research and the optimal use of preventative and integrated treatment interventions to achieve improved outcomes, enhanced survival and quality of life for the cancer patient.
The manuscript management system is completely online and includes a very quick and fair peer-review system, which is all easy to use. Visit http://www.dovepress.com/testimonials.php to read real quotes from published authors. 